\title{
Blood Oxygen Transport in the Early Avian Embryo
}

\author{
ROSEMARIE BAUMANN AND HANS-JÜRGEN MEUER \\ Physiologisches Institut, Universität Regensburg, Regensburg; and Zentrum Physiologie, \\ Medizinische Hochschule Hannover, Hannover, Federal Republic of Germany
}

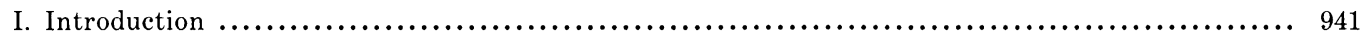

A. Ontogeny of hemoglobin types and red blood cell populations in the avian embryo ........... 942

II. Boundary Conditions for Blood Oxygen Transport in the Early Embryo ..................... 943

A. Basic structure of extra- and intraembryonic circulatory system $\ldots \ldots \ldots \ldots \ldots \ldots \ldots \ldots \ldots \ldots . . \ldots 43$

B. Determination of $\mathrm{pH}$ and carbon dioxide and oxygen partial pressures in vitelline and

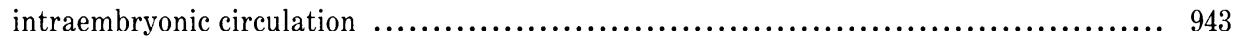

C. Determination of oxygen partial pressure and $\mathrm{pH}$ in embryonic tissue ................... 946

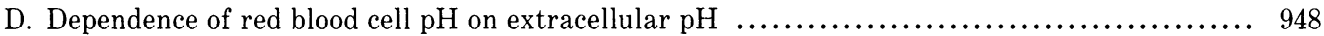

E. Assessment of diffusion conditions for oxygen transfer ................................ 949

F. Oxygenation in vitelline microcirculation: determination of capillary transit times and kinetics

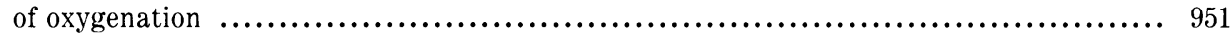

G. Effect of central shunt on intraembryonic oxygen supply .............................. 952

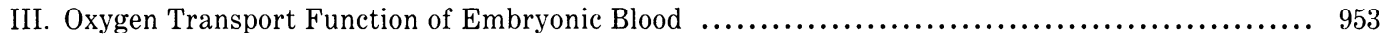

A. In vitro studies of isolated specific embryonic hemoglobins: effects of $\mathrm{pH}$, carbon dioxide, and

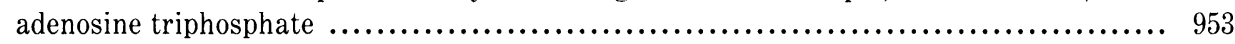

B. Red blood cell organic phosphate pattern .......................................... 954

C. Influence of organic phosphates on aggregation of hemoglobin P and hemoglobin D ........ 955

D. Oxygen-binding properties of embryonic blood between days $3-8$ of development ........... 956

E. Calculation of in situ blood oxygen saturation and content in various parts of embryonic

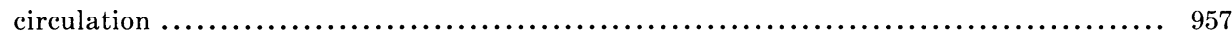

F. Estimation of intraembryonic oxygen transport rates ............................... 959

IV. Adaptive Changes of Oxygen Transport and Red Blood Cell Development During Exposure to

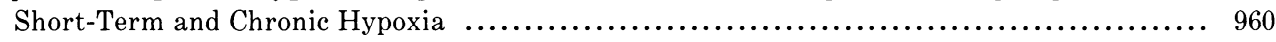

A. Effect of hypoxia on oxygen pressure in embryonic circulation $\ldots \ldots \ldots \ldots \ldots \ldots \ldots \ldots \ldots \ldots \ldots \ldots . . . .696$

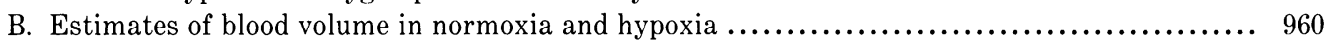

C. Influence of oxygen pressure on timing of switch from embryonic to adult hemoglobin ....... 961

D. Influence of hypoxia on red blood cell-phosphate pattern, carbonic anhydrase activity, and

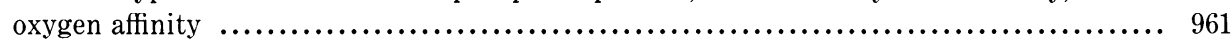

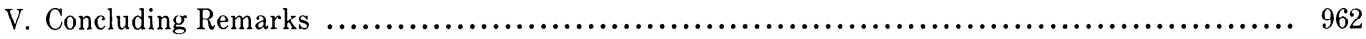

\section{INTRODUCTION}

The avian embryo for a long time has been a favorite object of study for the respiratory physiologist, since more than any other embryo of higher vertebrates it allows easy access to well-specified stages of development. The first attempt to study properties of embryonic hemoglobin of developing avian embryos was carried out on chick embryos by Hall (70).

The special problems imposed on late embryos by the diffusion limitation of gas transfer across the eggshell and shell membranes have been systematically analyzed in the chick embryo, and corresponding data for the oxygen and carbon dioxide transport properties have been obtained by several groups from approximately day 8 of incubation through development. Thus the general physiology of blood gas transport of the avian embryo, as studied in the chick, is well documented for the later period of development, and the in- terested reader can profit from several extensive monographs covering almost any aspect in this field $(33,90$, 104, 118).

Strictly speaking, those studies dealt with gas transport in avian fetuses, since the period of embryogenesis ends at about day 6 of development.

However, functional data about the properties of primitive red blood cells of early embryos are needed to understand why the blood of vertebrates contains a unique set of embryonic hemoglobins and why such a complicated pattern of erythropoiesis and hemoglobin synthesis prevails during embryonic development.

With the advent of micromethods for the study of blood oxygen-binding properties and the application of microelectrode techniques to determine parameters such as $\mathrm{pH}$, oxygen partial pressure $\left(\mathrm{PO}_{2}\right)$, and carbon dioxide partial pressure $\left(\mathrm{PCO}_{2}\right)$ in situ, attempts have been made in recent years to bridge the gap in knowledge. With the help of these techniques, gas transport in 
the chick embryo has now been characterized from day 3 of development onward.

Moreover, the primary structure of the specific embryonic hemoglobins of the chick is now completely known; it has thus become possible to some extent to analyze functional properties in terms of the molecular structure of embryonic hemoglobin.

It is the aim of this review to give a concise description of the current state of knowledge. In addition we emphasize those areas where data are still scarce in the hope of attracting other developmental physiologists into this somewhat neglected field.

Of necessity the view presented is somewhat biased, since in several cases we have had to rely only on our own experimental data.

\section{A. Ontogeny of Hemoglobin Types and Red Blood Cell Populations in the Avian Embryo}

Similar to all other vertebrate embryos analyzed so far, the avian embryo produces a specific set of embryonic hemoglobins during the first stage of development. They are synthesized by the first population of red blood cells (primitive red blood cells) that arises in the yolk sac, which is the principal site of erythropoiesis in early development $(31,54)$.

In the chick embryo visibly hemoglobinized red blood cells appear at $\sim 26-38 \mathrm{~h}$ of incubation in the blood islands that are found in a horseshoe-shaped area caudal from the embryo proper (31). A closed circulatory system is established after $\sim 48 \mathrm{~h}$ of incubation, allowing convective transport between the embryo and the yolk sac. The vascularized part of the yolk sac (area vasculosa) is the principal gas exchange organ during early development, i.c., until the beginning of the second week of incubation. Analyses of the hemoglobin pattern of the primitive red blood cells of the chick embryo revealed two major and two minor hemoglobins (30) whose chain compositions as well as amino acid sequences have been completely worked out during the last 10 years (36-39, $56,58,114,115)$. The hemoglobin types and their chain compositions are given in Table 1.

TABLE 1. Hemoglobin types of embryonic blood

\begin{tabular}{|c|c|c|c|}
\hline Hemoglobin & & Chain & Location \\
\hline $\mathrm{HbP}$ & $\pi_{2}$ & \multirow{2}{*}{$75 \%$} & \multirow{2}{*}{ Primitive RBCs } \\
\hline $\mathrm{HbP}^{\prime}$ & $\pi_{2}^{\prime}$ & & \\
\hline $\mathrm{HbE}$ & $\alpha_{2}^{\mathrm{A}}$ & $\left.\epsilon_{2}\right]_{25 \%}$ & \multirow{2}{*}{ Primitive RBCs } \\
\hline $\mathrm{HbM}$ & $\alpha_{2}^{\mathrm{D}}$ & $25 \%$ & \\
\hline $\mathrm{IIbA}$ & $\alpha_{2}^{\mathrm{A}}$ & $\beta_{2}$ & \multirow{2}{*}{ Definitive RBCs } \\
\hline $\mathrm{HbD}$ & $\alpha_{2}^{\mathrm{D}}$ & $\beta_{2}$ & \\
\hline $\mathrm{HbH}$ & $\alpha_{2}^{\mathrm{A}}$ & $\beta^{\mathrm{H}}$ & $\begin{array}{l}\text { Transient minor component in } \\
\text { definitive RBCs of prehatch, } \\
\text { chick embryo, and hatchling }\end{array}$ \\
\hline
\end{tabular}

$\mathrm{Hb}$, hemoglobin; RBCs, red blood cells. Nomenclature follows Brown and Ingram (30).
Comparative studies on other avian embryos suggest that the principal pattern of embryonic hemoglobin types and hemoglobin synthesis is the same among the species $(41,123)$.

In the chick embryo, primitive red blood cells are the principal red blood cell population until day 6 of development. By that time a second generation of red blood cells, definitive red blood cells, enters the vascular bed (31). These cells are unable to produce embryonic hemoglobin; instead they synthesize the two adult hemoglobins $\mathrm{A}$ and $\mathrm{D}(\mathrm{HbA}$ and $\mathrm{HbD})$, as well as a minor hemoglobin component $\mathrm{HbH}$. In adult chicken red blood cells the ratio of $\mathrm{HbA}$ to $\mathrm{HbD}$ is $\sim 3: 1$. In contrast the first population of definitive red blood cells produces $\mathrm{HbD}$ in excess of $\mathrm{HbA}(31)$, and the same has been observed for duck embryos (41). It is only during the later course of development that the final ratio of $\mathrm{HbA}$ to $\mathrm{HbD}$ is established. As shown in section $\operatorname{III} D$, the high amount of $\mathrm{HbD}$ found in early definitive red blood cells may have significant consequences for their oxygenbinding properties and function in oxygen transport.

In contrast to mammalian embryos where embryonic and adult hemoglobins may be produced in the same cell, hemoglobin synthesis in avian embryos is strictly lineage specific $(19,44,45,120)$. By an ingenious set of experiments with xenogenic and allogenic chimeras constructed of yolk sac and embryo proper, the group of Dieterlen-Lievre $(20,51,52-54,84,87)$ has demonstrated that the stem cells for permanent definitive erythropoiesis are of intraembryonic origin, presumably arising in the wall of the aorta (48).

Primary yolk sac erythropoiesis is responsible for the production of all primitive red blood cells and the first definitive cell population. Primary yolk sac erythropoiesis lacks, however, a stem cell compartment with the capacity for self-renewal $(53,99)$; thus the final size of the primitive and first definitive red blood cell population is arising from primary yolk sac erythropoiesis determined by the number of cells initially committed to the erythroid pathway.

An unsettled question is the molecular mechanism controlling the switch in hemoglobins. Work in this area has primarily concentrated on nuclear factors that control the stage-specific expression of the globin genes. The principal alignment of the genes coding for the $\alpha$ chains follows their sequential expression during development (58). A specific switching activity has not yet been demonstrated. Available evidence indicates that the regulation of globin gene expression involves 1) nuclear transcription factors that confer the ability for constitutive expression of globin genes in general, 2) stage-specific selectors responsible for the choice of globin type expressed at a given time, and 3) possibly transacting cytoplasmic factors having a pronounced influence on globin chain expression $(85,102,108)$. With regard to epigenetic influences, there is some evidence that in avian embryos the timing of the switch can be altered in response to changes in ambient oxygen pressure (17).

Furthermore, the correct timing process of the 
switch from primitive to definitive erythropoiesis apparently depends on a minimum of structural integrity of the yolk sac environment; although even parts of yolk sac kept in organ culture produce the correct sequential pattern of erythropoiesis, i.e., first primitive red blood cells and then the definitive red blood cells, dispersion of yolk sac tissue in suspension culture invariably causes both cell types and hemoglobins to develop at the same time $(68,69,138)$. This strongly suggests that the micromilieu of the yolk sac and short-range interactions between cells are important for the timing process (138).

Unlike red blood cells of adult animals that, excepting pathological states, enter the circulation as postmitotic cells, the primitive red blood cells enter the circulation as immature erythroblasts and complete their terminal differentiation, including several mitoses, inside the circulation. This is especially pertinent for those cells that enter the circulation directly after the fusion of the circulatory system; these cells mature as a cohort and are an excellent model for the study of ongoing differentiation processes. There is some evidence that primitive red blood cells are also recruited from extravascular erythropoietic sites in the yolk sac from day 4 of development onward. Support for this comes from the study of the cell population kinetics that demonstrate that the rate of growth of the red blood cell population after day 4 of development cannot be explained by the mitotic frequency of circulating red blood cells (43).

Thus immature primitive red blood cells, unlike all other red blood cells, have functional characteristics that allow them to proliferate rapidly and at the same time carry out their oxygen transport function in an adequate way.

\section{BOUNDARY CONDITIONS FOR BLOOD OXYGEN TRANSPORT IN THE EARLY EMBRYO}

\section{A. Basic Structure of Extra- and Intraembryonic Circulatory System}

In the chick embryo, blood islands appear toward the end of the first day of incubation. The endothelial cells form lumina enclosing primitive blood corpuscles and anastomose with neighoring blood islands, thus forming the primary extraembryonic blood vessel system. Concomitantly, primary endothelial tubes develop in the intraembryonic tissue. When these vessels join the extraembryonic vessels, continuity of circulation is established.

In the chick embryo, blood cells begin to circulate at day 2 of incubation. The driving force for blood circulation is generated by the primitive U-shaped heart. It pumps the blood through the short ventral aorta and the aortic arches into the dorsal aorta and the carotid arteries. From the dorsal aorta arise the omphalomesenteric arteries and the umbilical arteries that supply the vitelline and the allantoic circulation, respectively. The venous blood, which is returned by the extraembryonic and intraembryonic veins, is collected in the sinus venosus before it enters the heart at the atrial side.

The vitelline circulation supplies the embryonic tissue with food material absorbed from the yolk and up to about day 6 of incubation provides for the respiratory gas exchange with the environment. When the allantoic sac develops and fuses with the chorion (around day 8) respiratory function is successively transferred to the blood vessels of the newly formed chorioallantoic membrane. These stages of development are, however, not considered in this paper.

The vascularized area of the yolk sac is roughly circular. It spreads rapidly in a radial direction and reaches a diameter of $\sim 4 \mathrm{~cm}$ at day 4. The major blood vessels are the paired lateral vitelline arteries and the paired lateral vitelline veins, as well as the unpaired anterior and posterior vitelline veins. The area vasculosa is enclosed by the terminal sinus that collects blood from distal capillaries and that is drained by the anterior and posterior vitelline veins and by branches of the lateral vitelline veins.

The branching pattern of arteries and veins is dichotomous, thus giving rise to a treelike topology, whereas the capillaries, in particular near the terminal sinus, form a frequently meshed network.

In contrast to the adult, both the circulatory system that takes up oxygen from the environment (extraembryonic) and the circulation supplying the tissue (intraembryonic) share the same passage through the heart. This parallel arrangement of blood vessel loops acts as an arterial-to-venous shunt, setting special conditions for oxygen transport to tissue that are considered particularly in the following section.

\section{B. Determination of $p H$ and Carbon Dioxide and Oxygen Partial Pressures in Vitelline and Intraembryonic Circulation}

\section{Technique and technical problems}

Oxygen transport and acid-base status have been documented extensively from day 8 of incubation $(28,50$, 126) but not in earlier stages of development, since conventional techniques of acid-base analysis cannot be applied due to the small sample volumes. Instead these parameters have to be determined with microelectrodes.

The measurement itself can only be performed after partial removal of the eggshell and membranes, thereby eliminating part of the diffusion resistance, creating the possible error that too high $\mathrm{PO}_{2}$ values and too low $\mathrm{PCO}_{2}$ values are measured. As shown in section II $E$, the major diffusion resistance is located inside the area vasculosa itself, which substantially reduces the magnitude of the error.

Lomholt (86) was the first to measure $\mathrm{Po}_{2}$ in the early embryo. He removed the eggshell and the outer shell membrane just above the air space and inserted 
the microelectrode through the intact inner shell membrane and recorded $\mathrm{PO}_{2}$ profiles in the area adjacent to the embryo proper. Although this method leaves the extraembryonic diffusion barrier partially intact, it has, due to the opaqueness of the inner shell membrane, one major disadvantage; it is not possible to determine the exact location of the site of measurement. Nevertheless, the major finding from this study was that the $\mathrm{Po}_{2}$ values close to the embryo were exceedingly low at day 3 of development and sometimes near zero.

The most extensive study of $\mathrm{PO}_{2}, \mathrm{pH}$, and $\mathrm{PCO}_{2}$ inside the embryo and attached extraembryonic circulation has used a slightly different approach, insofar as no attempt was made to preserve the integrity of the outer diffusion barrier, i.e., eggshell and shell membranes. This disadvantage of removing the diffusion barrier was taken into account to be able to make measurements at precisely located sites. Aside from a possible reduction of the diffusion resistance, a second source of error to be taken into account is a change in the oxygen consumption under conditions where the eggshell is removed. This error, however, can be excluded, since Hoiby et al. (72) found that removal of the eggshell had no immediate effect on the oxygen uptake. Finally, one has to consider the error of the $\mathrm{PO}_{2}$ measurements that is introduced by the aerobic metabolism of the red blood cells and that could cause a substantial difference between the end-capillary $\mathrm{PO}_{2}$ and the $\mathrm{PO}_{2}$ measured in the anterior and posterior vitelline veins.

Calculations based on the data of Grima et al. (65) have shown that the maximum error introduced is in the range of 1 Torr/s; given the fact that transit times from capillaries to the vitelline vein are only a few seconds (Meuer, unpublished observation), this does not cause a substantial deviation of vitelline vein $\mathrm{PO}_{2}$ versus end-capillary $\mathrm{PO}_{2}(92)$.

Three types of electrodes have been successfully used for the blood gas measurements. Recessed-tip microelectrodes of the Whalen type were used to determine $\mathrm{PO}_{2}(92)$. Tissue and blood $\mathrm{pH}$ were determined with microelectrodes that use a liquid exchanger for the detection of protons (1). Microelectrodes for determination of $\mathrm{PCO}_{2}$ were constructed according to the description of Bomsztyk and Calalb (26) but were adapted to be able to measure $\mathrm{PCO}_{2}$ at values of $<20$ Torr (97). A survey of the extra- and intraembryonic sites chosen for the measurements of $\mathrm{pH}, \mathrm{PO}_{2}$, and $\mathrm{PCO}_{2}$ is given in Figs. 1 and 2.

\section{Oxygen partial pressure in embryonic blood}

The mean values of the $\mathrm{Po}_{2}$ in extraembryonic and intraembryonic blood vessels are summarized in Table 2 (92). In the 4-day-old embryo the $\mathrm{Po}_{2}$ of the extraembryonic blood vessels ranges from 45.4 Torr in the vitelline arteries to 80.9 Torr in the anterior and posterior vitelline veins. These numbers increase significantly by day 6 of incubation.

Although the eggshell and the shell membranes

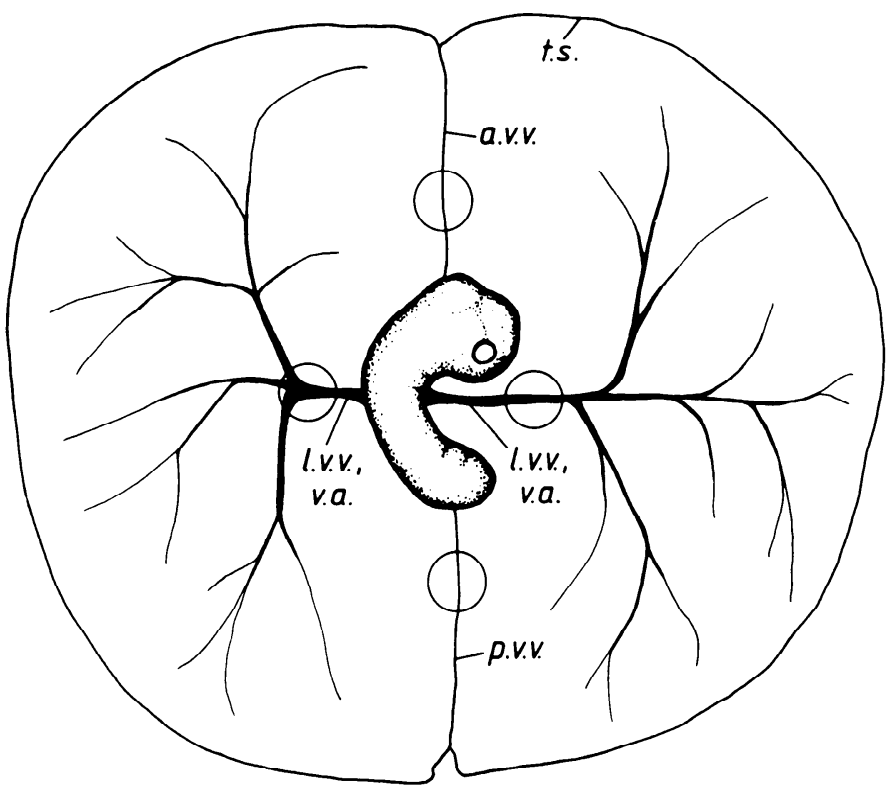

FIG. 1. Schematic of principal vessels of yolk sac vascular system in early chick embryo. $\mathrm{O}_{2}$ partial pressure $\left(\mathrm{PO}_{2}\right), \mathrm{pH}$, and $\mathrm{CO}_{2}$ partial pressure $\left(\mathrm{PCO}_{2}\right)$ were measured in lateral vitelline veins (lvv), vitelline arteries (va) (which are mostly covered by lateral veins and therefore not drawn separately), and in anterior and posterior vitelline veins (avv and pvv), which drain terminal sinus (ts). Sites of measurement are marked by circles.

had been removed before the measurements, the highest $\mathrm{PO}_{2}$ value determined in the anterior and posterior vitelline veins at day 6 was only about two-thirds of the environmental $\mathrm{PO}_{2}$ (mean value 149 Torr). These substantial $\mathrm{PO}_{2}$ differences between environment and blood suggest that the oxygen uptake by the embryo is diffusion limited. There is also a significant difference between the $\mathrm{PO}_{2}$ values measured in the anterior and posterior vitelline veins and the lateral vitelline veins. In the lateral vitelline veins $\mathrm{PO}_{2}$ is significantly lower than in the anterior and posterior vitelline veins. This could be due either to a difference in the diffusion resistance or to morphological and/or rheological heterogeneity of the capillary network that effects the amount of admixture of blood with low oxygen saturation from vitelline arteries. This point is referred to in section II $E$.

The mean $\mathrm{PO}_{2}$ in the dorsal aorta is nearly the same as in the vitelline arteries. This is to be expected, because the vitelline arteries originate from the dorsal aorta.

Mean venous $\mathrm{PO}_{2}$ values in the intraembryonic circulation range from 16.1 to 34.6 Torr, displaying a gradient from cranial to caudal. Because at this stage of development the caudal region is less vascularized than the head region (95), it seems that the lower $\mathrm{Po}_{2}$ in the caudal veins may reflect a lower oxygen supply of the caudal region rather than higher oxygen consumption.

Because of the parallel arrangement of the intraand extraembryonic circulation, the blood from the vitelline veins, which is rich in oxygen, is mixed with nearly desaturated intraembryonic venous blood before entering the intraembryonic circulation. Therefore the 


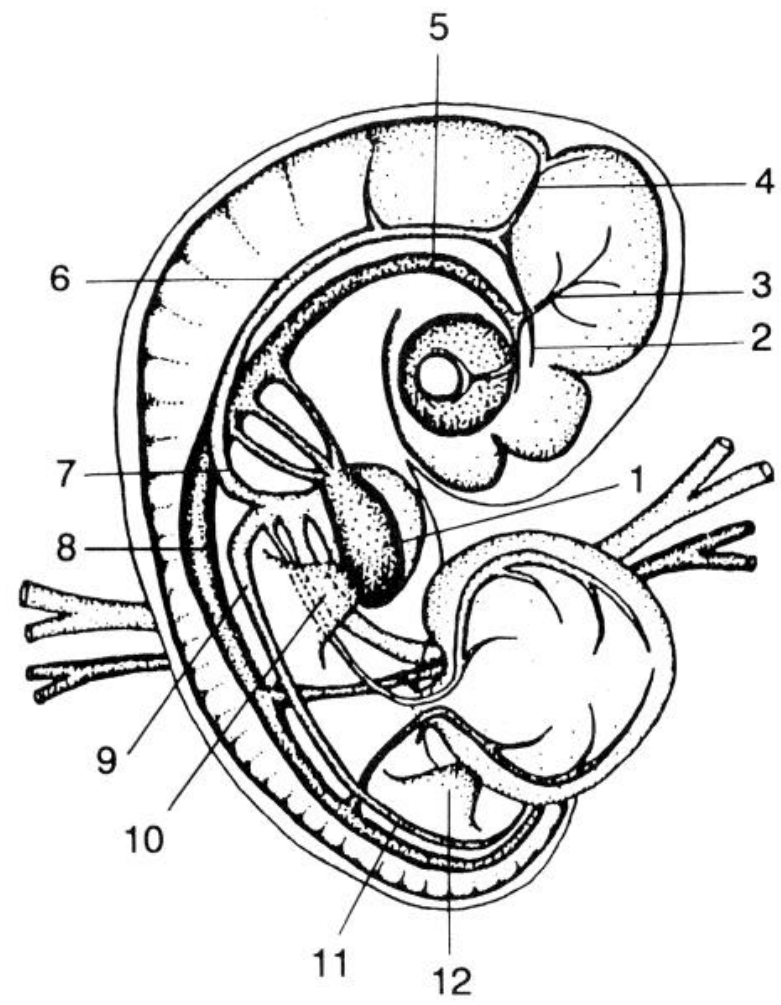

FIG. 2. Schematic of 4-day-old chick embryo. Approximate sites of $\mathrm{Po}_{2}$ and $\mathrm{pH}$ measurements in intraembryonic blood vessels are indicated. 1) heart, 2) anterior cerebral vein, 3 ) bigerminal artery, 4) middle cerebral vein, 5) internal carotid artery, 6 ) internal jugular vein, 7 ) anterior vena cava, 8 ) dorsal aorta, 9) posterior cardinal vein, 10 ) wing bud, 11) vein of tail, 12) leg bud. [From Meuer and Tietke (97).]

$\mathrm{PO}_{2}$ of the arterial blood that supplies the embryonic tissue with oxygen is substantially lower than the vitelline venous $\mathrm{PO}_{2}$. Mean arterial $\mathrm{PO}_{2}$ values of $<50$ Torr were measured. Consequently, one must expect that the $\mathrm{PO}_{2}$ in the embryonic tissue is also very low, which is confirmed by the measurements described in section II $C$.

\section{3. $\operatorname{Blood} \mathrm{pH}$}

The $\mathrm{pH}$ was measured in the lateral vitelline veins, in the vitelline artery, in the jugular vein, and in the heart (96; Table 3). In the first series of measurements the embryo was exposed to air. In a second series of measurements ambient carbon dioxide concentration was increased stepwise from 0 to $3 \%$ to evaluate the effect of hypercapnia on blood and interstitial $\mathrm{pH}$.

The highest $\mathrm{pH}$ values were found in the vitelline veins ( $\mathrm{pH} 8.0$ at day 4 and 7.89 at day 6 ). These high $\mathrm{pH}$ values are caused by the low $\mathrm{PCO}_{2}$ of the vitelline blood, which can be extrapolated from the $\mathrm{PCO}_{2}$ measurements in the air cell (82) of the early embryo. Direct measurements of blood $\mathrm{PCO}_{2}(97)$ have confirmed these values.

The $\mathrm{pH}$ values measured in the vitelline arteries are $\sim 0.2 \mathrm{pH}$ unit lower than in the vitelline veins. Similar venous-to-arterial $\mathrm{pH}$ differences have been reported by Tazawa (124) and Tazawa et al. (127) for the blood of the
TABLE 2. Mean $\mathrm{PO}_{2}$ in vitelline and intraembryonic blood vessels of 4- and 6-day-old chick embryos

\begin{tabular}{|c|c|c|}
\hline \multirow[b]{2}{*}{ Vessel Type } & \multicolumn{2}{|c|}{ Mean $\mathrm{PO}_{2}$, Torr } \\
\hline & Day 4 & Day 6 \\
\hline \multicolumn{3}{|c|}{ Extraembryonic } \\
\hline Vitelline arteries & $45.4 \pm 4.7$ & $49.1 \pm 6.3^{*}$ \\
\hline Lateral vitelline veins & $63.7 \pm 9.5$ & $80.9 \pm 11.9^{*}$ \\
\hline Anterior/posterior vitelline veins & $80.9 \pm 13.4$ & $102.4 \pm 16.5^{*}$ \\
\hline \multicolumn{3}{|c|}{ Intraembryonic } \\
\hline Dorsal aorta & $44.9 \pm 6.9$ & $48.2 \pm 7.2$ \\
\hline Internal carotid artery & $41.3 \pm 2.9$ & $46.5 \pm 3.4^{*}$ \\
\hline Bigerminal artery & $41.6 \pm 4.9$ & $45.4 \pm 4.9$ \\
\hline Anterior cerebral vein & & $34.6 \pm 4.8$ \\
\hline Middle cerebral vein & $33.9 \pm 7.0$ & $28.8 \pm 8.2$ \\
\hline Internal jugular vein & $29.4 \pm 7.2$ & $32.2 \pm 4.8$ \\
\hline Anterior vena cava & $26.0 \pm 2.2$ & $29.6 \pm 7.1$ \\
\hline Vein of wing bud & & $28.3 \pm 6.9$ \\
\hline Posterior cardinal vein & $21.8 \pm 5.6$ & $25.3 \pm 4.8$ \\
\hline Vein of leg bud & & $20.9 \pm 8.0$ \\
\hline Vein of tail & $16.1 \pm 4.5$ & \\
\hline
\end{tabular}

Values are means $\pm \mathrm{SD}$. Mean ambient $\mathrm{O}_{2}$ partial pressure $\left(\mathrm{PO}_{2}\right)$ during the measurements was 149 Torr. ${ }^{*}$ Significant difference $(P<0.05)$ between days 4 and 6.

chorioallantoic vein and artery from day 10 onward through development. Because the vitelline arteries originate from the dorsal aorta, the $\mathrm{pH}$ in intraembryonic arteries should be close to the $\mathrm{pH}$ determined for the vitelline arteries.

The lowest $\mathrm{pH}$ is present in the intraembryonic veins. Mean values determined in the jugular vein were $\mathrm{pH} 7.64$ and 7.42 at days 4 and 6 , respectively.

The $\mathrm{pH}$ data obtained in the heart vary much more than the other blood $\mathrm{pH}$ values. This is probably due to incomplete mixing of intraembryonic venous blood of low $\mathrm{pH}$ with blood of the vitelline veins, which has the highest $\mathrm{pH}$. This was demonstrated using dye injection

TABLE 3. Change in blood $\mathrm{pH}, \mathrm{PCO}_{2}$, and $\mathrm{HCO}_{3}^{-}$ concentration in chick embryos between days 4 and 17

\begin{tabular}{lcccc}
\hline \hline \multicolumn{1}{c}{ Location } & Day 4 & Day 6 & Day 10 & Day 17 \\
\hline $\begin{array}{l}\text { Extraembryonic vein } \\
\text { pH }\end{array}$ & $8.00 \pm 0.05$ & $7.89 \pm 0.08$ & 7.636 & 7.461 \\
$\quad \mathrm{PCO}_{2}$, Torr & $4.2 \pm 0.49$ & $7.0 \pm 0.9$ & 11.8 & 33.0 \\
$\quad\left[\mathrm{HCO}_{3}^{-}\right]$, mmol/1 & 12.3 & 15.3 & 12.4 & 23.3 \\
Extraembryonic artery & & & & \\
$\quad$ pH & $7.80 \pm 0.04$ & $7.66 \pm 0.07$ & 7.430 & 7.305 \\
$\quad \mathrm{PCO}_{2}$, Torr & $6.9 \pm 0.4$ & $10.6 \pm 1.0$ & 18.2 & 44.5 \\
$\quad\left[\mathrm{HCO}_{3}^{-}\right]$, mmol/1 & 11.9 & 12.9 & 11.9 & 21.8 \\
$\begin{array}{l}\text { Jugular vein } \\
\text { pH }\end{array}$ & $7.64 \pm 0.07$ & $7.42 \pm 0.06$ & & \\
$\begin{array}{l}\text { Heart } \\
\text { pH }\end{array}$ & $7.68 \pm 0.10$ & $7.67 \pm 0.17$ & & \\
\hline
\end{tabular}

Values are means or means $\pm \mathrm{SD}$. At days 4 and 6 , values refer to blood of vitelline circulation $(96,97)$; values for days 10 and 17 refer to chorioallantoic blood (27). $\left[\mathrm{HCO}_{3}^{-}\right]$was calculated using the Henderson-Hasselbach equation $\left(\mathrm{p} K^{\prime}=6.1\right) . \mathrm{PCO}_{2}, \mathrm{CO}_{2}$ partial pressure. 
into different vitelline veins, which indicated that the flow through the heart tube is laminar and that the preferential direction of the dye stream varies with the site of injection (136). Therefore the measured $\mathrm{pH}$ of the blood in the heart will depend on the position of the microelectrode tip within the lumen of the heart.

Previous measurements of the blood $\mathrm{pH}$ of the chorioallantoic vein have shown that there is a progressive decrease of the blood $\mathrm{pH}$ with increasing age of the embryo (127). As the increase in aerobic metabolic rate is not accompanied by a corresponding increase of the diffusion capacity, it results in accumulation of carbon dioxide (and in consequence a reduction of $\mathrm{pH}$ ), as well as in a reduction of the $\mathrm{PO}_{2}$ in the blood. The present results combined with those of Tazawa et al. (127) show that between days 4 and 17 of development there is a decrease in the $\mathrm{pH}$ of the arterialized blood leaving the gas exchange area of $>0.5 \mathrm{pH}$ unit from $\sim 8.0$ at day 4 to $<7.5$ in the prehatching period.

The measured $\mathrm{pH}$ differences between the venous and arterial parts of the early embryonic circulation are also quite substantial at both days 4 and 6 . The maximum difference experimentally recorded amounts to $0.47 \mathrm{pH}$ unit (7.89 in the vitelline vein vs. 7.42 in the jugular vein at day 6). Therefore the Bohr effect (i.e., the $\mathrm{pH}$-dependent decrease of the oxygen affinity, with increasing concentration of protons) plays an important role in the oxygen supply of the embryo. The very alkaline $\mathrm{pH}$ in the vitelline veins is essential for a high oxygen saturation of the arterialized blood, and the low $\mathrm{pH}$ in intraembryonic veins allows a desaturation of the blood at a fairly high $\mathrm{PO}_{2}(12 \%$ oxygen saturation at a $\mathrm{PO}_{2}$ of 32 Torr in the jugular vein at day 6 ), facilitating oxygen transfer to the embryonic tissues.

An increase of the environmental $\mathrm{PCO}_{2}$ is followed by a substantial fall of blood $\mathrm{pH}$ by as much as $0.3-0.5$ $\mathrm{pH}$ unit with $3 \% \mathrm{CO}_{2}(96)$, which interferes directly with oxygen uptake in early development. The high $\mathrm{pH}$ values found in the vitelline vein under physiological conditions are necessary for sufficient oxygenation of the embryonic blood. The arteriovenous difference in oxygen saturation between vitelline vein and artery is $52 \%$ at day 4 and $70 \%$ at day 6 . In the presence of 8 Torr $\mathrm{PCO}_{2}$ the arteriovenous difference in oxygen saturation is reduced to $31 \%$ at day 4 and $58 \%$ at day 6 (96). This substantial reduction reflects the fact that the cooperativity of oxygen binding to embryonic chick hemoglobin is much higher than to adult hemoglobin $(16,82)$, with maximum $n$ values, which are a measure of that binding, of $\sim 7$ in the upper saturation range. Even though this behavior is very advantageous to counter the effects of the central venous shunt present in the embryonic heart, inasmuch as the ensuing fall in $\mathrm{PO}_{2}$ is minimized $(16,82)$, it also leads to a considerable decrease of the oxygen saturation of the vitelline vein if only a moderate decrease of the oxygen affinity is encountered. Thus "acidosis" of any kind can jeopardize oxygen supply to the early embryo, particularly since at this stage the embryo is unable to counter hypoxia by an increase in red blood cell mass (17) or cardiac output (64).

\section{Blood carbon dioxide partial pressure and acid-base status}

The mean blood $\mathrm{PCO}_{2}$ values (97) determined under normoxic conditions at days $4-6$ of development range between 4.2 and 10.6 Torr. These data are compatible with the previously measured low $\mathrm{PCO}_{2}$ in the air space of the egg [2-3 Torr (82)] and with the high blood $\mathrm{pH}$ values.

From measurements in elevated environmental carbon dioxide concentrations the in ovo relationship between $\log \mathrm{PCO}_{2}$ and $\mathrm{pH}$ has been obtained (Fig. 3).

Estimates of the carbon dioxide dissociation curves of the blood were obtained from the sum of the bicarbonate concentration and the respective concentration of physically dissolved carbon dioxide (Fig. 4). Carbon dioxide bound to hemoglobin was neglected, because the hemoglobin concentration is low [20 g/l at day 4 and 35 $\mathrm{g} / \mathrm{l}$ at day $6(17,111)]$. For the same reason, carbon dioxide concentration differences between oxygenated and deoxygenated blood are negligible. This is also supported by the data of Tazawa (126), which demonstrated that even at day 10 the haldane effect was insignificant.

Standard bicarbonate concentrations determined from the carbon dioxide dissociation curves were 29.4 and $24.4 \mathrm{mmol} / \mathrm{l}$ at 4 and 6 days, respectively. The respective buffer values obtained from the bicarbonate versus $\mathrm{pH}$ relationship were 28.8 and $21.4 \mathrm{mmol} / \mathrm{l}$.

Between days 4 and $6 \mathrm{pH}$ decreases from 8.0 to 7.83 in the vitelline veins and from 7.8 to 7.66 in the vitelline arteries. These changes are not only caused by the rise in $\mathrm{PCO}_{2}$ but also by a metabolic acidification, which is indicated by the drop in the standard bicarbonate concentration. This tendency seems to continue to day 10 , since at this stage the acid-base status is characterized by increased blood $\mathrm{PCO}_{2}$ values and negative base excess (124).

\section{Determination of Oxygen Partial Pressure and $p H$ in Embryonic Tissue}

\section{Oxygen partial pressure in embryonic tissue}

Tissue $\mathrm{PO}_{2}$ was measured in seven different embryonic locations (brain, lens, neck, wing bud, back, leg bud, tail) using oxygen microelectrodes (95). The electrodes were inserted randomly within the natural limits of the respective location at a depth of $\sim 1 \mathrm{~mm}$. The mean and median values for head (brain, lens, neck) and trunk (wing bud, back, leg bud, tail) are summarized in Table 4.

The $\mathrm{PO}_{2}$ data exhibit a large scatter between the sites of measurement. Furthermore, in each site of measurement the readings range between zero and arterial $\mathrm{PO}_{2}$ values. The frequency distributions are asymmetric, with maximum frequency near zero $\mathrm{PO}_{2}$ (Fig. 5). The highest median value was found in the head at day 4 (8.4 Torr). The median decreases with embryonic age and 
FIG. 3. $\mathrm{CO}_{2}$ titration curves of blood of vitelline arteries (art) and veins (ven) of 4- and 6-dayold chick embryos obtained by stepwise increase of ambient $\mathrm{CO}_{2}$ concentration. Symbols, measured mean values; solid lines, calculated by linear regression (4 days (4d): $\log \mathrm{PCO}_{2}=15.1-1.81 \times \mathrm{pH} ; 6$ days $\left.(6 \mathrm{~d}): \log \mathrm{PCO}_{2}=14.3-1.72 \times \mathrm{pH}\right)$. [From Meuer and Tietke (97).]

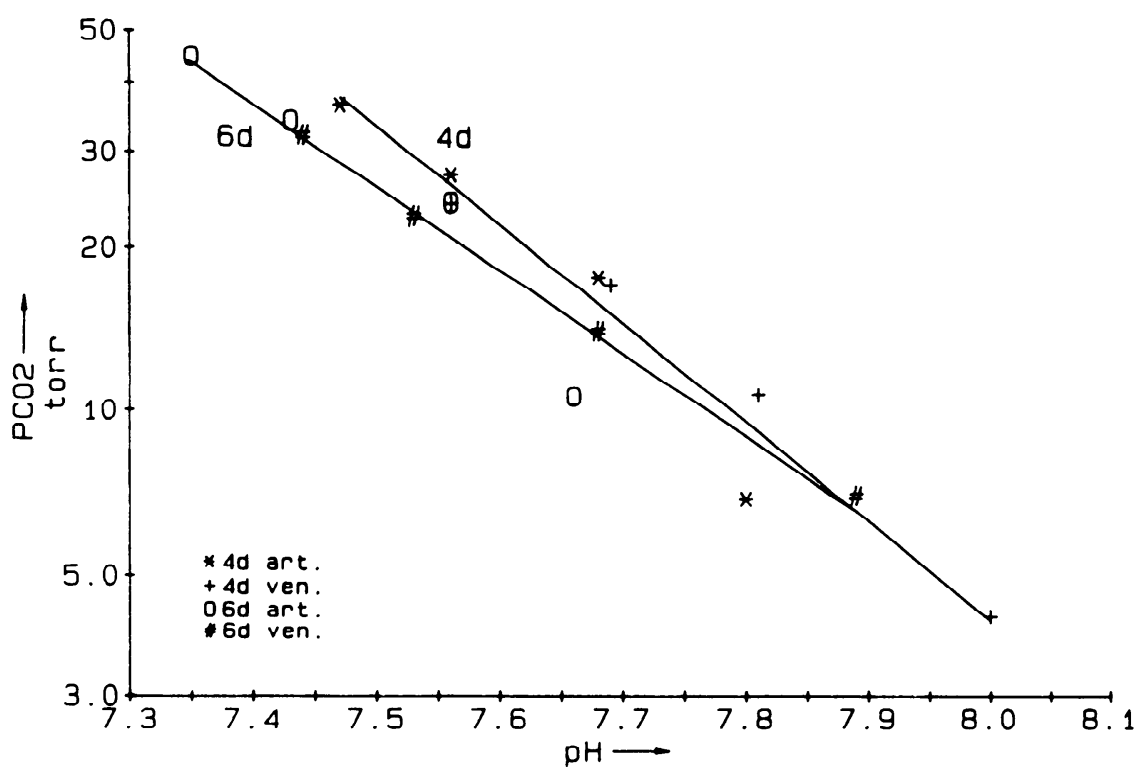

each day is significantly lower in the trunk than in the head.

A wide range in the tissue $\mathrm{PO}_{2}$ data was expected, since because of the random selection of the site of measurement the electrodes were located at different distances from a blood vessel. However, it is remarkable that despite these uncertainties, those $\mathrm{PO}_{2}$ values that appear with the highest frequency (i.e., $40-60 \%$ of all values) are found in the lowest $\mathrm{PO}_{2}$ group (0-5 Torr; Fig. 5).

The $\mathrm{Po}_{2}$ gradient between capillary blood and tissue determines the rate of oxygen diffusion from blood to tissue. For a given blood $\mathrm{PO}_{2}$ this gradient is defined by the tissue $\mathrm{PO}_{2}$. Therefore the extremely low $\mathrm{Po}_{2}$ values found in the embryonic tissue indicate that the embryo extracts as much oxygen from the capillary blood as possible. This implies that even under conditions of normal oxygen supply the utilization of available oxygen is

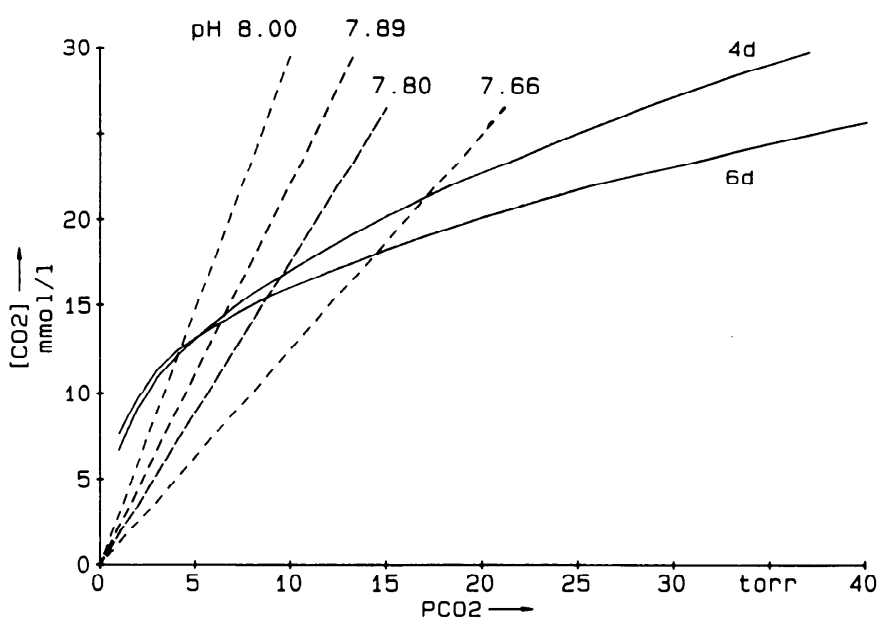

FIG. 4. Calculated $\mathrm{CO}_{2}$ dissociation curves for chick embryonic blood at 4 and 6 days of incubation. Dashed lines, iso-pH curves. [From Meuer and Tietke (97).] maximized. This suggests that the aerobic metabolic rate is indeed limited by the oxygen availability during early development. Consequently, a diminished oxygen supply due to lowering blood $\mathrm{PO}_{2}$ will directly affect the growth rate of the embryo. On the other hand, increases in blood $\mathrm{PO}_{2}$ will accelerate growth. This is in accord with experimental observations (3).

\section{Measurements of tissue $p H$}

The tissue $\mathrm{pH}$ values display a significant craniocaudal gradient at day 4 with $\mathrm{pH}$ falling from 7.68 (cranial) to as low as 7.47 in the caudal region (96; Table 5). At day 6, however, this gradient no longer exists, and values range from $\mathrm{pH} 7.52$ to $\mathrm{pH} 7.61$.

Interstitial $\mathrm{pH}$ has been measured in one other study by Gillespie and McHanwell (62), who investigated early developmental stages (up to 22 somites, which corresponds to $\sim 53 \mathrm{~h}$ of incubation). They reported interstitial $\mathrm{pH}$ values of $7.8-8.1$ at $34-35^{\circ} \mathrm{C}$, and they also found a sizeable craniocaudal $\mathrm{pH}$ gradient.

Our measured interstitial $\mathrm{pH}$ values are lower, and

TABLE 4. Tissue $\mathrm{Po}_{2}$ measured with oxygen microelectrodes in different locations of chick embryo at 4, 5, and 6 days of incubation

\begin{tabular}{cccc}
\hline \hline & \multicolumn{3}{c}{$\mathrm{Po}_{2}$, Torr } \\
\cline { 2 - 4 } Location & Day 4 & Day 5 & Day 6 \\
\hline Head & & & \\
Mean & 11.4 & 10.8 & 8.4 \\
Median & 8.4 & 6.4 & 4.2 \\
Trunk & & & \\
Mean & 8.3 & 9.3 & 6.6 \\
Median & 4.8 & 3.6 & 2.6 \\
\hline
\end{tabular}

At each day the differences between head and trunk are significant (U-test, $P<0.05)$. 

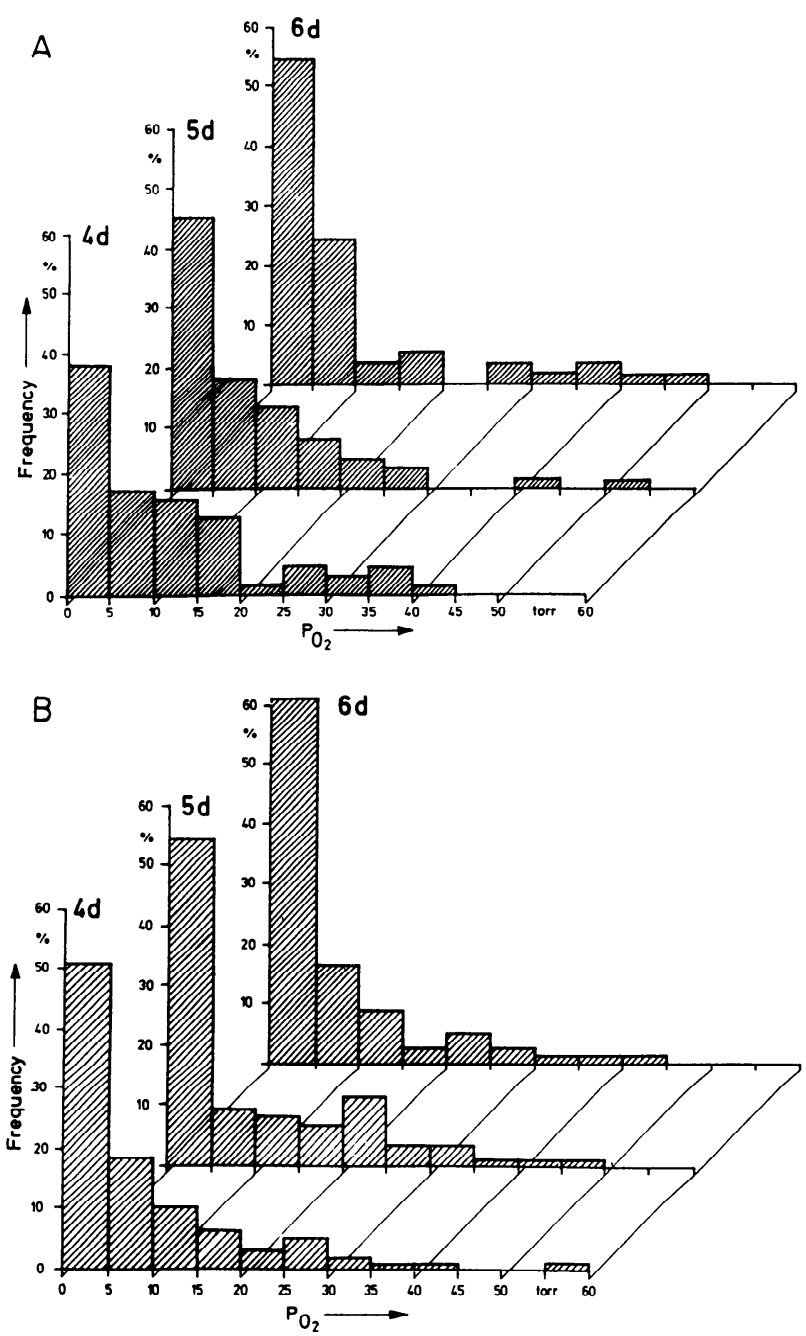

FIG. 5. Frequency distribution of tissue $\mathrm{Po}_{2}$ measurements in head (brain, lens, neck; $A$ ) and in trunk (tail, back, wing, bud, leg bud; $B$ ) at 4,5 , and 6 days of incubation.

a craniocaudal gradient is apparent only at day 4. Therefore the existing results suggest that the highest interstitial $\mathrm{pH}$ is present around day 2 of development.

It is perhaps no coincidence that there is also a craniocaudal gradient for $\mathrm{Po}_{2}$ in the intraembryonic veins (92). In the 4-day-old embryo the $\mathrm{PO}_{2}$ of the veins decreases from cranial to caudal, but at day 6 this gradient is no longer apparent. The presence of $\mathrm{pH}$ and $\mathrm{Po}_{2}$ gradients presumably reflects significant regional differences in oxygen supply and/or utilization, which have also been reported for very early development (106). This is also supported by the finding that between days 4 and 6 the dry mass of the head region increases from $34 \%$ of total embryonic dry mass to $48 \%$ (95), which indicates a substantial rise of the metabolic rate in the cranial region. Judging by the measured $\mathrm{pH}$ values the collapse of the craniocaudal $\mathrm{pH}$ gradient between days 4 and 6 seems predominantly due to a progressive acidification of the cranial region.

An increase in the ambient $\mathrm{PCO}_{2}$ causes an immediate fall of the tissue $\mathrm{pH}$ similar to the $\mathrm{pH}$ decrease ob- served in the blood. With $3 \%$ ambient carbon dioxide, tissue $\mathrm{pH}$ decreases by $\sim 0.4$ unit (96).

It is known that incubation in elevated $\mathrm{PCO}_{2}$ leads to increased mortality and malformations in young embryos even when a normal $\mathrm{PO}_{2}$ is maintained (cf. Ref. 112). One reason for this phenomenon may be the effect of decreased $\mathrm{pH}$ on cell proliferation.

Several studies have demonstrated a permissive role of cell $\mathrm{pH}$ in the promotion of cell division (cf. Ref. 66 ) or a direct increase of cell $\mathrm{pH}$ after stimulation of cells with mitogens. Furthermore, it has been demonstrated that the cellular binding of insulin and insulinlike growth factors, which are present early in avian development, is maximal at alkaline $\mathrm{pH}$ values and is substantially decreased by an increase of the proton concentration. (6). A pH-dependent reduction of growth factor binding may also lead to arrested or disturbed development.

\section{Dependence of Red Blood Cell $p H$ on Extracellular $p H$}

The $\mathrm{pH}$ values for embryonic blood cover a range of nearly $0.5 \mathrm{pH}$ unit between various parts of the embryonic circulation at day 4 or 6 . The $\mathrm{pH}$ of the arterialized blood leaving the gas exchanger via vitelline vein/ chorioallantoic vein decreases from $\mathrm{pH} 8.0$ at day 4 (96) to $\sim 7.46$ at day 18 (125).

This raises the question as to how the red blood cell controls its cell $\mathrm{pH}$ in the face of the constantly changing external conditions. Red blood cell $\mathrm{pH}$ plays a crucial role in the regulation of hemoglobin function. In the first place protons by themselves are allosteric effectors of the hemoglobin molecule (namely the Bohr effect). Second, the binding of organic phosphates to hemoglobin (they are the most important allosteric effectors) is profoundly $\mathrm{pH}$ dependent, decreasing with increasing $\mathrm{pH}$ (21-23), and, finally, red blood cell $\mathrm{pH}$ affects the metabolic pathways connected with the synthesis of organic phosphate cofactors, especially 2,3-diphosphosphoglyceric acid (2,3-DPG) (cf. Ref. 32).

It is not clear if the ongoing proliferative activity of circulating primitive erythroblasts requires specific adjustments of cell $\mathrm{pH}$ during the cell cycle.

In adult red blood cells, chloride, bicarbonate, and proton distributions are in equilibrium because of the

TABLE 5. Mean tissue $p H$ values of 4- and 6-day-old chick embryos

\begin{tabular}{ccc}
\hline \hline Location & Day4 & Day 6 \\
\hline 1 & $7.68 \pm 0.15$ & $7.60 \pm 0.14$ \\
2 & $7.63 \pm 0.14$ & $7.56 \pm 0.13$ \\
3 & $7.51 \pm 0.09$ & $7.61 \pm 0.09$ \\
4 & $7.47 \pm 0.13$ & $7.57 \pm 0.06$ \\
5 & $7.50 \pm 0.13$ & $7.52 \pm 0.02$ \\
\hline
\end{tabular}

Locations of measurements were spaced evenly in craniocaudal direction along dorsolateral part of the embryo (location 1, head; location 5, tail). Depth of insertion of microelectrode was $\sim 1 \mathrm{~mm}$. 
presence of the band 3 anion exchanger (cf. Ref. 71). Rapid readjustment of $\mathrm{pH}$ after perturbations is achieved via the Jacobs-Stewart cycle, which in addition to band 3 requires the presence of intracellular carbonic anhydrase to be effective under physiological conditions.

At equilibrium the distribution ratios of $\mathrm{Cl}^{-}, \mathrm{HCO}_{3}^{-}$, and $\mathrm{OH}^{-}$calculated from red blood cell and plasma concentrations are such that $\mathrm{r}_{\mathrm{Cl}}=\mathrm{r}_{\mathrm{HCO}_{3}}=\mathrm{r}_{\mathrm{OH}}$, and in essence red blood cell $\mathrm{pH}$ can be calculated from the chloride distribution ratio, which is primarily dependent on the net charge and osmotic activity of the impermeant anions inside the red blood cell, i.e., phenomenologically it follows the Donnan distribution.

Because the electrogenic conductance of chloride exceeds that of other ions, its distribution also sets the membrane potential (83). If one compares the values of red blood cell $\mathrm{pH}$ of various species of birds and mammals under resting conditions (i.e., with arterial $\mathrm{pH}$ between $\mathrm{pH} 7.4$ and 7.5), there is remarkably little divergence; most cell $\mathrm{pH}$ values are in the region of $7.2(7,10)$. The measured values for the membrane potential of adult human and chick red blood cells are also very similar $(-10$ to $-15 \mathrm{mV})(80,83)$.

In the early chick embryo, carbonic anhydrase activities of embryonic red blood cells have been measured from day 4 of incubation through hatching (15). At this stage the activity of carbonic anhydrase is $<10 \%$ of the adult value, and even lower activities occur during midterm incubation (15). Electrophoretic analysis of red blood cell membranes of chick embryos first detected band 3 in small amounts at day $3(34,35)$, which then rapidly increased during the succeeding days, reaching adult values by day 6 of development. Thus both components required for rapid $\mathrm{pH}$ equilibrium across the red blood cell membrane are present early in development.

Direct measurements of red blood cell $\mathrm{pH}$ have been carried out at days 4 and 6 of development. The results demonstrated that under physiological conditions, i.e., extracellular $\mathrm{pH}=7.9$, the cell $\mathrm{pH}$ is $\sim 0.6$ unit lower than the plasma $\mathrm{pH}$, whereas the $\mathrm{pH}$ difference calculated from the chloride distribution was much less, i.e., only $0.3 \mathrm{pH}$ unit $(12,16,121)$.

Moreover, the distribution of chloride across the red blood cell membrane could be altered in the expected manner when external chloride was replaced by impermeable anions, whereas the distribution of protons was only slightly affected $(12,121)$. Subsequent measurements of the membrane potential of primitive red blood cells from 4- and 6-day-old chick embryos demonstrated that the membrane potential is apparently dominated by a proton conductance. Consequently the membrane potential is much more negative than observed for adult red blood cells [about -38 to $-44 \mathrm{mV}$ at days 6 and 4 , respectively (59)]. These results imply that the heteroexchange (bicarbonate-chloride exchange) mediated by band 3 protein is impaired, since with a normal mode of bicarbonate-chloride exchange a disequilibrium between protons and chloride ions cannot be maintained. Indeed, preliminary measurements of the kinetic proper- ties of band 3 in primitive embryonic red blood cells indicate that bicarbonate transfer is much slower in early development compared with adult red blood cells, whereas chloride transfer is much less affected (U. Sieger, J. Brahm, and R. Baumann, unpublished observations). Determinations of the membrane potential and cell $\mathrm{pH}$ as functions of developmental age demonstrate that equilibrium of chloride distribution, membrane potential, and proton distribution are achieved by the end of the second week of incubation, presumably due to normalization of band 3 function and a decreased importance of the proton conductance $(8,12)$. Because all of these measurements were carried out in whole blood, it is possible that substantial differences exist between the various red blood cell subpopulations.

Nevertheless, the continuous change of the proton distribution ratio that causes a decrease of the $\mathrm{pH}$ unit difference between red blood cell and plasma from 0.6 to $\approx 0.2 \mathrm{pH}$ between days 6 and 16 of development helps to maintain cell pH nearly constant, i.e., between 7.2 and 7.3 , despite the continuing acidification of the extracellular compartment.

Several questions arise from these findings regarding 1) the nature of the proton conductance of primitive red blood cells and its regulation, 2) the kind of mechanism responsible for the altered bicarbonate transport characteristics of band 3 protein during early development, and 3) the transport mechanisms that keep red blood cell chloride concentration in primitive red blood cells above electrochemical equilibrium. In conclusion, it can be said that the unusual blood acid-base conditions under which early embryonic red blood cells have to carry out their function are mirrored by a red blood cell $\mathrm{pH}$ regulation that is completely different from the one present in adult red blood cells.

\section{E. Assessment of Diffusion Conditions for Oxygen Transfer}

Diffusion plays an important role for the respiratory gas exchange between embryo and environment. After the egg is laid, the embryo is directly exposed to the gas partial pressures in the ambient atmosphere that are $\sim 150$ Torr for oxygen at sea level and close to 0 Torr for carbon dioxide. The gas fluxes between embryo and environment depend on 1) the gas partial pressures in the blood of the extraembryonic circulation, 2) the effective gas exchange area, and 3) the thickness and diffusive properties of the material separating the red blood cells from the environment. In the early embryonic stages when respiratory gas exchange takes place via the blood vessels of the yolk sac membrane, the diffusion pathway is mainly formed by the eggshell, the outer and inner shell membrane, and a layer of egg albumen on top of the area vasculosa.

A large number of publications deal with the morphology and diffusive properties of the eggshell and the shell membranes (e.g., see Refs. 25, 79, 81, 103, 107, 119, 


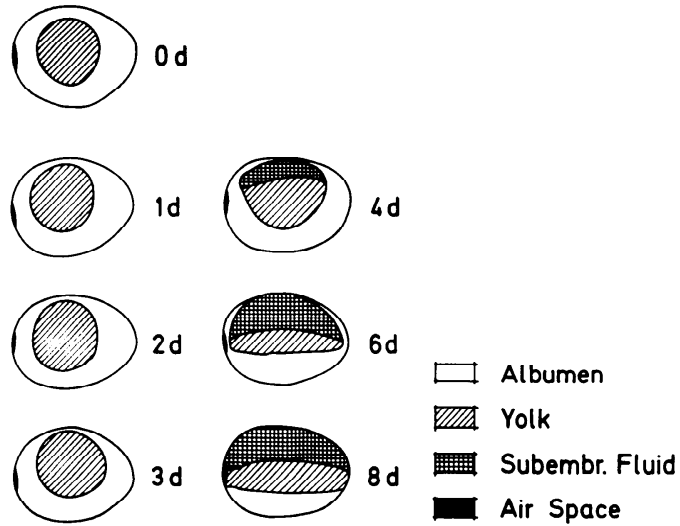

FIG. 6. Position and shape of yolk within egg during incubation drawn from cross sections of frozen eggs. Subembryonic fluid was not distinguishable from yolk before day 4 .

128-132, 134). Mentioning all would be beyond the scope of this review.

Eggshell and outer shell membrane exhibit a low resistance to gas diffusion, since the pores of the eggshell as well as the space between the fibers of the outer membrane are gas filled. The inner shell membrane is moist at the onset of incubation so that gas diffusion through it can be treated as diffusion through an aqueous solution. However, the water content of the inner membrane decreases rapidly between days 2 and 6 $(81,119)$, and consequently the resistance to gas diffusion is reduced accordingly. Thus Kayar et al. (79) determined the oxygen permeability of the eggshell and shell membranes and found a mean value of $0.12 \times 10^{-6}$ $\mathrm{ml} \cdot \mathrm{s}^{-1} \cdot \mathrm{cm}^{-2} \cdot$ Torr $^{-1}$ at day 3 that increased to $0.68 \times$ $10^{-6} \mathrm{ml} \cdot \mathrm{s}^{-1} \cdot \mathrm{cm}^{-2} \cdot$ Torr $^{-1}$ by day 6 .

The resistance caused by the albumen layer on top of the area vasculosa is also subject to change. Up to about day 6 of incubation there is no tight connection between the embryo and the inner shell membrane, which alone would guarantee an even thickness of the albumen layer. Close apposition of the area vasculosa to the inner shell membrane is caused by movement of egg yolk during the first week of incubation (94).

The basis for the movement of egg yolk is buoyancy, caused by different densities of albumen and yolk; there is also evidence for biochemical processes weakening the gel structure of the thick albumen (94).

As a result of these forces, the yolk sphere, which is initially located in the center of the egg, moves to the upper pole and in its upper part approaches the shape of the egg shell (Fig. 6). As a consequence of the change in the yolk position and shape, the blood vessels of the yolk sac membrane come into close contact with the inner shell membrane, which facilitates the gas exchange with the environment. The distance between blood capillaries and inner shell membrane has not been directly measured, but estimates range between 20 and $30 \mu \mathrm{m}$ at day 4 (109).

From day 2 of incubation onward the area vasculosa of the yolk sac spreads along the yolk sac surface. The
TABLE 6. Area of yolk sac surface included by terminal sinus of area vasculosa between days 3 and 6 of incubation

\begin{tabular}{lcccc}
\hline & Day 3 & Day 4 & Day 5 & Day 6 \\
\hline Mean area $\pm \mathrm{SD}$, & & & & \\
$\mathrm{mm}^{2}$ & $558 \pm 102$ & $1,389 \pm 219$ & $2,753 \pm 398$ & $3,750 \pm 208$ \\
Sample size & 17 & 28 & 20 & 20 \\
\hline
\end{tabular}

Measurements were performed by the following method: in a transilluminated egg the area of shade of the terminal sinus was drawn on the eggshell with water-resistant ink. After boiling the egg the marked area of the eggshell including the membranes was cut off by a fraise, and the membranes were gently stripped from the eggshell. To obtain a plain surface the membranes were cut radially. Then the area was measured by a semi-automatic planimeter. (From H.-J. Meuer and C. Bertram, unpublished data.)

shape of the vascularized area is circular, with a diameter of $\sim 27 \mathrm{~mm}$ at day 3, increasing to $69 \mathrm{~mm}$ by day 6 . The increase of the size of the area enclosed by the terminal sinus is listed in Table 6 . The area covered by the embryo is $<5 \%$ of the area surrounded by the terminal sinus (estimated from photographs; Meuer, unpublished observations). Therefore the data given in Table 6 are about equal to the vascularized area involved in respiratory gas exchange.

Mean capillary diameter in the area vasculosa is 23 $\mu \mathrm{m}$ at day 4. This parameter has been evaluated for randomly selected locations using fluorescent video microscopic techniques. To visualize the vessel lumen a solution of fluorescein-labeled dextran was injected into the circulation (101). The diameters were measured using digital video image analysis (93).

The capillary length per unit area has been determined in the same series of experiments described in section II $F$, also using video image analysis. Assuming that the projection plane of the capillaries is the effective area for respiratory gas exchange and using the measured value for the vascularized area, one calculates a total diffusion area of $216 \mathrm{~mm}^{2}$ at day 4 (Table 7).

With these data one can estimate the diffusion capacity of the area vasculosa for oxygen, i.e., the oxygen flux per unit pressure difference. The total oxygen up-

TABLE 7. Parameters defining respiratory gas exchange between environment and extraembryonic circulation in a 4-day-old chick embryo

\begin{tabular}{lcc}
\hline \multicolumn{1}{c}{ Parameter } & Sample Size & Value \\
\hline $\begin{array}{l}\text { Capillary diameter, } \mu \mathrm{m} \\
\begin{array}{l}\text { Capillary length per unit area, } \\
\mathrm{mm} / \mathrm{mm}^{2}\end{array}\end{array}$ & 541 & $23.2 \pm 6.0$ \\
$\begin{array}{l}\text { Capillary projection plane per } \\
\text { unit area, } \mathrm{mm}^{2} / \mathrm{mm}^{2}\end{array}$ & 20 & $6.69 \pm 1.3$ \\
$\begin{array}{l}\text { Vascularized area, } \mathrm{mm}^{2} \\
\text { Capillary gas exchange area, } \\
\mathrm{mm}^{2}\end{array}$ & 28 & $0.155^{*}$ \\
& & $1,389 \pm 219$ \\
\hline
\end{tabular}

Values are means or means \pm SD. * Calculated numbers. (From H.-J. Meuer and C. Bertram, unpublished data.) 
TABLE 8. Microcirculatory parameters of vitelline capillary system of 4-day-old chick embryos

\begin{tabular}{lccc}
\hline \multicolumn{1}{c}{ Parameter } & Count & Mean \pm SD & Median \\
\hline $\begin{array}{l}\text { Red blood cell velocity, } \mu \mathrm{m} / \mathrm{s} \\
\text { Segment length, } \mu \mathrm{m}\end{array}$ & 893 & 193 & 169 \\
$\begin{array}{l}\text { Length of arteriovenous } \\
\quad \text { channel, } \mu \mathrm{m} \text {. }\end{array}$ & 893 & $117 \pm 66$ & \\
Capillary transit time, s & 802 & 434 & 386 \\
\hline
\end{tabular}

From H.-J. Meuer and C. Bertram, unpublished data.

take of the egg at day 4 is $117 \mathrm{nl} / \mathrm{s}(61)$. The major part of this flux is utilized by the extraembryonic structures, whereas only $8 \%$ will serve for the oxygen supply of the embryo (Meuer, unpublished observations).

The driving force for the diffusion of oxygen can be estimated from the $\mathrm{PO}_{2}$ measurements in the extraembryonic circulation. If it is assumed that the mean capillary $\mathrm{PO}_{2}$ is the mean of the vitelline venous and vitelline arterial $\mathrm{PO}_{2}$, the mean pressure gradient between ambient air and capillary is calculated to be 95 Torr. With these data one arrives at a minimum estimate of the diffusion capacity of $0.0985 \mathrm{nl} \cdot \mathrm{s}^{-1} \cdot$ Torr $^{-1}$. It should be pointed out that this result is a very rough estimate calculated under the assumption that the effective gas exchange area is identical with the morphologically determined capillary area. In section II $F$, however, we show that the capillary transit time varies to such an extent that there are, on the one hand, capillary pathways functioning like arteriovenous shunts and, on the other hand, arteriovenous connections with redundant length.

\section{F. Oxygenation in Vitelline Microcirculation: Determination of Capillary Transit Times and Kinetics of Oxygenation}

The capillaries of the vitelline microcirculation form a highly meshed network. The entrances and exits of this network are connected by a multitude of capillary segments, meshed by nodes of three or four vessels. Because of this anatomic pattern, a variety of pathways through the network exists, which differs with respect to the number of segments, total length, transit time, and red blood cell flux.

Capillary transit time and other microcirculatory parameters were determined by Meuer and Bertram (93) after injection of fluorescent (fluorescein)-labeled red blood cells into the embryonic circulation (Table 8). Measurements were carried out on video images using an on-line digital video analyzing system. To describe the rheologic properties of the arteriovenous channels segment length, red blood cell velocity and labeled cell flux were determined for each capillary segment of randomly selected areas of the yolk sac circulation. These data were used to calculate the respective parameters of each arteriovenous channel of the area under investigation.

\section{Microcirculatory properties of vitelline capillary system}

It seems to be a general characteristic of the vitelline capillary system that the values of each microcirculatory parameter are widely distributed. The arteriovenous channels are formed by between 1 and 13 capillary segments, the blood cell velocity ranges between 17 and $664 \mu \mathrm{m} / \mathrm{s}$ (mean value $193 \mu \mathrm{m} / \mathrm{s}$ ), and the red blood cells require transit times between 0.09 and $17 \mathrm{~s}$ for passage through the capillary network (Table 8; Fig. 7).

\section{Kinetics of oxygenation}

To get an estimate of the transit time required for complete oxygenation of the red blood cells, the kinetics of blood oxygenation were calculated in the following way. The physiological hemoglobin oxygen dissociation curve of the capillary blood was determined from the dissociation curves for vitelline arterial and venous blood at actual $\mathrm{pH}(96$; see sect. III $E)$. Because we know the $\mathrm{PO}_{2}$ and oxygen saturation at the arterial end of the capillaries and the ambient $\mathrm{PO}_{2}$, the diffusive oxygen uptake of the blood was calculated by Bohr's integration method.

However, this calculation requires knowledge of the diffusive capacity of the capillary system. Because this number has not been measured, we took for a first trial the minimum estimate value of $0.0985 \mathrm{nl} \cdot \mathrm{s}^{-1} \cdot \mathrm{Torr}^{-1}$.

To check the calculation, the oxygen saturation of the mixed vitelline venous blood was computed and compared with the oxygen saturation determined from $\mathrm{PO}_{2}$ measurements (92). Because blood flow and capillary transit time are heterogeniously distributed among the arteriovenous channels, the contribution of each channel to total vitelline venous oxygen saturation varies substantially. Furthermore, because of the nonlinear relationship between transit time and end-capillary oxygen saturation, the mean capillary transit time is an unsuitable figure to calculate the mean venous saturation. Therefore the oxygen flux of each arteriovenous

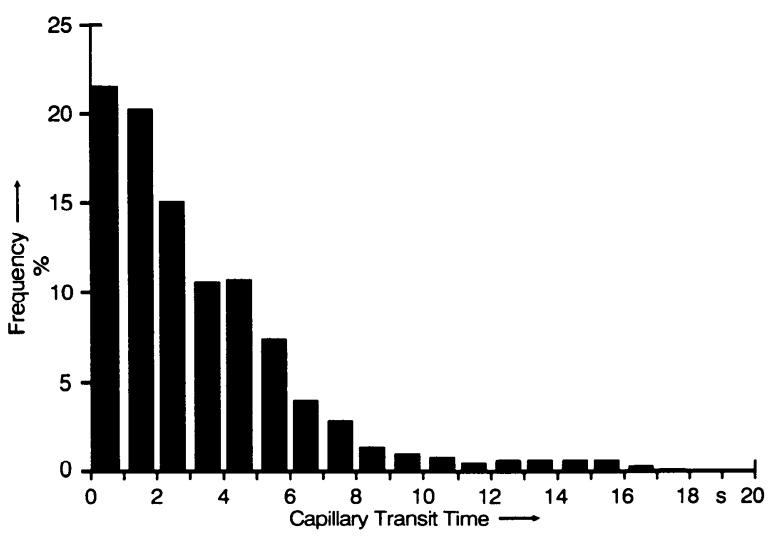

FIG. 7. Frequency distribution of capillary transit time in vitelline circulation of 4-day-old chick embryo. 
channel was computed separately and then added for the total flux.

With the use of the value of $0.0985 \mathrm{nl} \cdot \mathrm{s}^{-1} \cdot$ Torr $^{-1}$ for the diffusion capacity, the calculated vitelline venous $\mathrm{PO}_{2}$ was 52 Torr (55\% oxygen saturation), whereas the measured $\mathrm{PO}_{2}$ was 64 Torr (89\% oxygen saturation). Further calculation demonstrated that a value of $89 \%$ for vitelline venous oxygen saturation requires a diffusion capacity of at least $0.538 \mathrm{nl} \cdot \mathrm{s}^{-1} \cdot$ Torr $^{-1}$.

For a diffusive capacity of $0.0985 \mathrm{nl} \cdot \mathrm{s}^{-1} \cdot$ Torr $^{-1}$, a capillary transit time of $8.3 \mathrm{~s}$ is required for $99 \%$ oxygen saturation of the blood. This number was reduced to 1.5 $\mathrm{s}$ when a value of $0.538 \mathrm{nl} \cdot \mathrm{s}^{-1} \cdot$ Torr $^{-1}$ was used in the calculation.

Because the measured capillary transit times of the red blood cell range up to $17 \mathrm{~s}$ (Fig. 7), there is a considerable number of arteriovenous channels of which only a part of the total length is used for oxygen uptake. In the remaining section of the capillary pathway where the transit time is longer than required, hemoglobin is completely oxygen saturated, i.e., the diffusion gradient is zero. For the calculation of the first estimate of the diffusive capacity $\left(0.0985 \mathrm{nl} \cdot \mathrm{s}^{-1} \cdot\right.$ Torr $\left.^{-1}\right)$ it was assumed that the mean capillary $\mathrm{PO}_{2}$ is the mean value between arterial and venous $\mathrm{PO}_{2}$. This obviously overestimates the mean diffusion gradient, since it was not taken into account that in a substantial portion of the capillary network the blood $\mathrm{PO}_{2}$ is near ambient $\mathrm{Po}_{2}$. Therefore we believe that a diffusive capacity of 0.538 $\mathrm{nl} \cdot \mathrm{s}^{-1} \cdot$ Torr $^{-1}$ and the ensuing transit time for complete oxygenation of $1.5 \mathrm{~s}$ are fairly reasonable estimates.

Whatever the true oxygenation time may be, there is in every case also a substantial number of arteriovenous channels in which the transit time is shorter than required for complete oxygenation of the blood. This means that in the vitelline veins completely oxygenated blood is mixed with blood that is less oxygenated, thus reducing the vitelline venous oxygen saturation. This seems to be the main reason for the relatively low saturation of $89 \%$ determined for the vitelline venous blood at day 4 .

\section{G. Effect of Central Shunt on Intraembryonic Oxygen Supply}

The highly oxygen-saturated blood of the vitelline veins is shunted with the intraembryonic venous blood before it supplies the embryonic tissue with oxygen. Because the intraembryonic venous blood is nearly completely desaturated (40) but contributes the major part of the blood flow into the heart, the mixed arterial oxygen saturation is substantially lower than the vitelline venous saturation. For the same reasons the arterial $\mathrm{PO}_{2}$ is also reduced but not to the same extent, because the admixture of intraembyronic venous blood also affects the intraembryonic arterial $\mathrm{pH}$. Direct measurements show that the arterial $\mathrm{pH}$ is $\sim 0.2$ unit lower than the $\mathrm{pH}$ in the vitelline veins (96; Fig. 8). Because of the Bohr effect, the arterial $\mathrm{PO}_{2}$ is kept at a fairly high level.

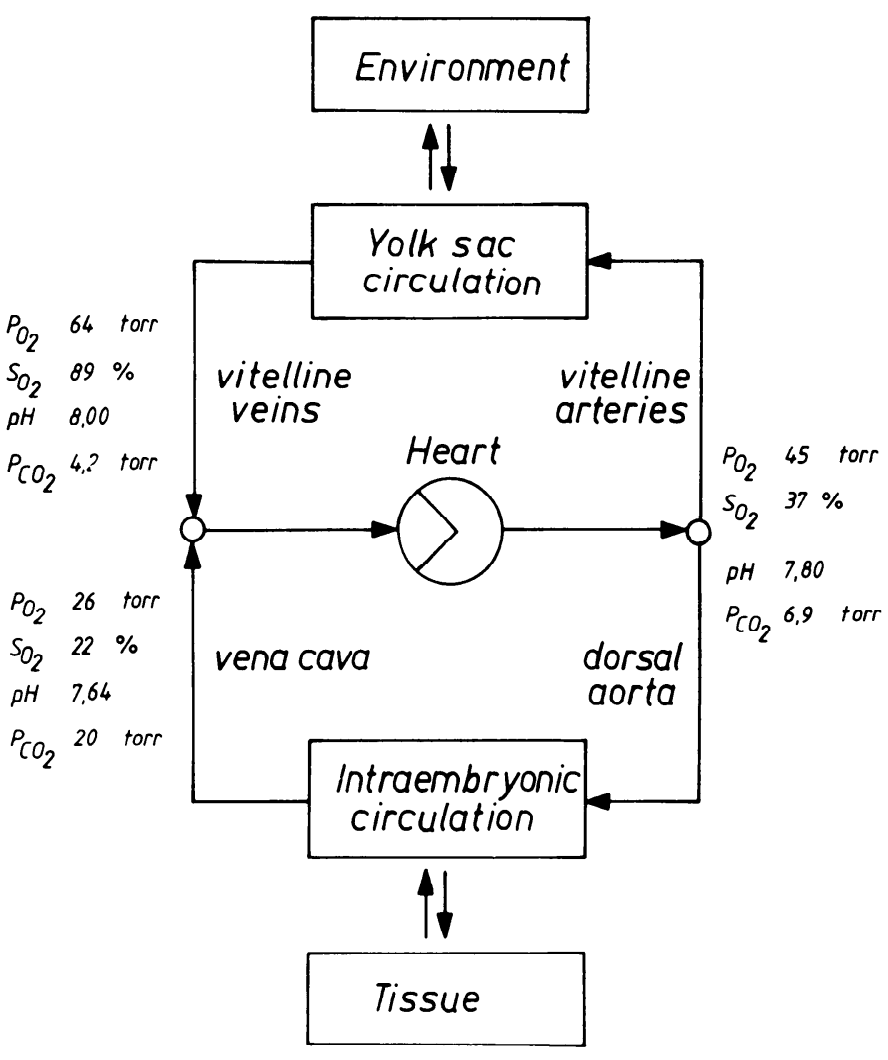

FIG. 8. Circulation block diagram and schematic of oxygen transport in early embryo with representative $\mathrm{PO}_{2}$ values (Torr) measured in 4-day-old chick embryo and corresponding oxygen saturation (\%) of blood obtained from oxygen hemoglobin curves $(96) . \mathrm{So}_{2}, \mathrm{O}_{2}$ saturation.

This seems to be essential for a sufficient oxygen supply to the embryonic tissue, since the arterial $\mathrm{Po}_{2}$ determines the diffusion gradient between blood and tissue as tissue $\mathrm{PO}_{2}$ is near zero.

The parallel arrangement of the intra- and extraembryonic circulation makes it possible to calculate the relative contributions of intra- and extraembryonic blood flow to total flow using the values for the oxygen saturation in different parts of the circulation (92). Because the oxygen flow through the heart (total flow) is equal to the sum of intra- and extraembryonic venous oxygen flow, the ratio of intraembryonic venous and total blood flow $\left(\dot{\mathrm{q}}_{\mathrm{iv}} / \dot{\mathrm{q}}_{\mathrm{t}}\right)$ is given by the equation

$$
\dot{\mathrm{q}}_{\mathrm{iv}} / \dot{\mathrm{q}}_{\mathrm{t}}=\left(\mathrm{S}_{\mathrm{ev}}-\mathrm{S}_{\mathrm{a}}\right) /\left(\mathrm{S}_{\mathrm{ev}}-\mathrm{S}_{\mathrm{iv}}\right)
$$

where $S_{a}, S_{e v}$, and $S_{i v}$ are the oxygen saturation of the blood in the arteries, the extraembryonic veins, and the intraembryonic veins, respectively. If we use the oxygen saturation in the lateral vitelline veins, the jugular vein (these vessels carry the main portion of venous blood flow), and the dorsal aorta, the percentage of blood flow from intraembryonic veins is calculated to be 77 and $84 \%$ of the total blood flow into the heart at days 4 and 6 , respectively (92). This result has recently been confirmed by Cirotto and Arangi (40). 


\section{OXYGEN TRANSPORT FUNCTION OF EMBRYONIC BLOOD}

The physiological function of hemoglobins and the effect of allosteric cofactors on their properties are commonly assessed through the measurement of the oxygen equilibrium curve from which two key functional parameters are extracted, namely, the oxygen pressure necessary for half saturation $\left(\mathrm{P}_{50}\right)$ as an indicator of hemoglobin oxygen affinity and the $n$ value as a measure for the cooperativity of oxygen binding. Both can be determined with Hill's empirical formula for the oxygen-binding curve, $\mathrm{y}=k\left(\mathrm{Po}_{2}\right)^{n}$, where $\mathrm{y}$ is the fractional saturation and $k$ is the dissociation constant. In its linearized version, $\log [\mathrm{y} /(1-\mathrm{y})]=\log k+n \log \mathrm{PO}_{2}$, it usually gives a satisfactory plot for the experimental data of many hemoglobins except at the upper and lower limits of the oxygen-binding curve where $n=1$. For most mammalian hemoglobins $n$ is in the range of 2.6-3 for the middle part of the oxygen equilibrium curve. The theoretical maximum $n$ value for a tetrameric protein like hemoglobin is $n=4$. Thus $n$ values $>4$ must result either from ligand-dependent association/dissociation phenomena of tetramer complexes or alternately from formation of a stable complex of several tetramers with intrinsically unchanged cooperativity where higher cooperativity can be induced via the action of allosteric effectors bound to this complex in a ligand-dependent fashion. For tetrameric hemoglobins, it has been shown that the $n$ value is decreased whenever the conformational transition on ligand binding is impaired or when the conformational equilibrium between high- and lowaffinity forms of hemoglobin is drastically shifted in favor of one conformation (cf. Ref. 32).

With regard to the hemoglobin affinity, it can be said that all known allosteric effectors of vertebrate hemoglobin, i.e., protons, carbon dioxide, inorganic anions such as chloride, as well as the organic phosphates [2,3DPG, ATP, GTP, and inositol pentakisphosphate ${ }^{-}$ $\left(\mathrm{IP}_{5}\right)$ ], cause a reduction of the oxygen affinity (usually expressed as an increase of the $\mathrm{P}_{50}$ ) due to preferential binding to deoxyhemoglobin. Detailed description of the molecular mechanisms involved can be found in references 23,32 , and 110 .

\section{A. In Vitro Studies of Isolated Specific Embryonic Hemoglobins: Effects of $p H$, Carbon Dioxide, and Adenosine Triphosphate}

Studies of the functional properties of isolated embryonic hemoglobins of higher vertebrates are scarce. In addition to the technical difficulties arising from the need to sample a large amount of primitive red blood cells for quantitative separation, the embryonic hemoglobins are also characterized by a greater instability than the corresponding adult hemoglobins with regard to autoxidation, which requires that separations are carried out in the presence of carbon monoxide, which
TABLE 9. $P_{50}$ and Bohr effect of embryonic and adult hemoglobin and 6-day embryonic blood

\begin{tabular}{|c|c|c|c|c|c|c|}
\hline & \multicolumn{4}{|c|}{$\mathrm{P}_{50}$, Torr } & \multirow{2}{*}{\multicolumn{2}{|c|}{$\begin{array}{c}\Delta \log \mathrm{P}_{50} / \Delta \mathrm{pH} \\
(\mathrm{pH} 6.7-7.2)\end{array}$}} \\
\hline & \multicolumn{2}{|c|}{ pH 6.7} & \multicolumn{2}{|c|}{ pH 7.2} & & \\
\hline & $-\mathrm{ATP}$ & $+\mathrm{ATP}$ & $-\mathrm{ATP}$ & $+\mathrm{ATP}$ & - ATP & + ATP \\
\hline $\mathrm{HbP}$ & 2.7 & 15.5 & 2.50 & 9.4 & -0.05 & -0.44 \\
\hline $\mathrm{HbP}^{\prime}$ & 3.10 & 14.8 & 2.80 & 7.3 & -0.08 & -0.61 \\
\hline $\mathrm{HbM}$ & 2.3 & 15.5 & 1.90 & 6.8 & -0.38 & -0.72 \\
\hline $\mathrm{HbE}$ & 6.0 & 50.1 & 3.4 & 20.4 & -0.49 & -0.78 \\
\hline \multirow{2}{*}{$\begin{array}{l}\text { Hb adult } \\
6 \text {-Day embryonic } \\
\text { blood }\end{array}$} & 12.4 & 87.3 & 7.4 & 35.62 & -0.44 & -0.78 \\
\hline & \multicolumn{2}{|c|}{98.1} & \multicolumn{2}{|c|}{43.8} & \multicolumn{2}{|c|}{-0.70} \\
\hline
\end{tabular}

Conditions for hemoglobin solutions: $0.31 \mathrm{mmol} \mathrm{Hb}_{4}$, total $\mathrm{Cl}^{-}$ $160 \mathrm{mmol}$, temperature $=37^{\circ} \mathrm{C}$. ATP was added in 10 -fold excess over $\mathrm{Hb}_{4} . \mathrm{O}_{2}$ half-saturation pressure $\left(\mathrm{P}_{50}\right)$ in embryonic blood is related to red blood cell $\mathrm{pH}$.

subsequently has to be removed. Additionally, the solubility of the embryonic hemoglobins at low temperature in media of low ionic strength is much lower than that of adult hemoglobins so that concentration of separated samples has to be carried out in media of moderate ionic strength, i.e., 0.1-0.15 M NaCl. We also observed that ultrafiltration under high pressure with the systems from various suppliers caused massive denaturation of the early embryonic hemoglobins, and therefore we have usually concentrated the hemoglobins using systems that rely on centrifugation to provide the necessary filtration pressure.

Continuous registration of the oxygen equilibrium curves of either separated embryonic hemoglobins or red blood cell preparations has been possible by using thin-film methods that need only a few microliters to complete one oxygen equilibrium curve (cf. Ref. 82).

Storage of the isolated hemoglobins is best at temperatures of $-80^{\circ} \mathrm{C}$ and below, and repeated freezethawing should be avoided, since it leads to artifacts. Because of the tendency for autoxidation the shelf life of carbon monoxide-free hemoglobin solutions at $4^{\circ} \mathrm{C}$ is again very limited; storage at this temperature should not extend the period necessary for completion of individual measurements.

The first systematic study of the properties of the major embryonic chick hemoglobins $\left(\mathrm{HbP} / \mathrm{P}^{\prime}\right)$ was carried out by Cirotto and Geraci (42), who found that the embryonic hemoglobins had a higher oxygen affinity than adult hemoglobin both in the absence and presence of organic phosphates. Their measurements were carried out at $20^{\circ} \mathrm{C}$. Our subsequent studies were carried out at $37^{\circ} \mathrm{C}$ to allow better comparison with the oxygenbinding properties of embryonic blood (16). The relevant data are presented in Table 9 . At $\mathrm{pH} 7.2$ and $37^{\circ} \mathrm{C}$ the $\mathrm{P}_{50}$ of the four hemoglobin components is very high when only chloride $(0.16 \mathrm{~mol})$ is present as allosteric effector. The cooperativity is normal ( $n$ values were between 2 and 3 for all 4 hemoglobins), and the $P_{50}$ values ranged from 1.9 Torr for $\mathrm{HbM}$ to 3.7 Torr for $\mathrm{HbE}$. The Bohr 
effect $\left(\Delta \log \mathrm{P}_{50} / \Delta \log \mathrm{pH}\right)$ determined in the physiological $\mathrm{pH}$ range is nearly absent for the two major embryonic hemoglobins, being -0.05 and -0.06 , respectively. The effect of carbon dioxide on the embryonic hemoglobins is very small (16) and in vivo is probably negligible, since 1) $\mathrm{PCO}_{2}$ is low (4-10 Torr in arterial and venous parts of the circulation), and 2) the binding of carbon dioxide to the $\alpha$-chain $\mathrm{NH}_{2}$ terminus is impossible due to acetylation (39) and at the $\beta$-chain $\mathrm{NH}_{2}$ terminus carbon dioxide has to compete with organic phosphates (cf. Ref. 32).

When the oxygen affinity is determined in the presence of a 10-fold excess of ATP over hemoglobin there is a 3 -fold decrease of the oxygen affinity of $\mathrm{HbP}$ and $\mathrm{HbP}^{\prime}$ compared with a 5 -fold increase for adult hemoglobin solutions.

Nevertheless, even in the presence of excess ATP the $\mathrm{P}_{50}$ is $<10$ Torr at $\mathrm{pH} 7.2$ and $37^{\circ} \mathrm{C}$ and thus substantially lower than the corresponding value for whole blood, which is 43.8 Torr. This large discrepancy strongly suggests that additional factors are involved in the control of embryonic blood oxygen affinity. The $\mathrm{pH}$ dependence of ATP binding to embryonic hemoglobin results in a substantial increase of the Bohr effect. Overall the in vitro results for the embryonic hemoglobins from chick are in good qualitative agreement with corresponding data for hemoglobin from mammalian embryos (29, 78, 135).

Phylogenetic analysis has shown that the embryonic $\alpha$-type chains diverged more than 300 million years ago, and all embryonic $\alpha$-type chains have maintained a high degree of homology (49). In contrast, the embryonic $\beta$-type chains are of recent origin and show close homology to the respective adult $\beta$-chains. Thus it seems reasonable to attribute the specific functional properties of embryonic hemoglobins to the specific $\alpha$-chains.

Indeed, a comparison of the oxygen affinity of the major embryonic chick hemoglobins with the minor embryonic $\mathrm{HbM}$ and $\mathrm{HbE}$ demonstrates that the high oxygen affinity is predominantly due to the specific type of $\alpha$-chain. Of the two adult chick $\alpha$-chains, it is the presence of the $\alpha^{\mathrm{D}}$-chain that confers a higher oxygen affinity on $\mathrm{HbM}$ and HbD. Czelusniak et al. (49) have pointed out that the $\alpha^{\mathrm{D}}$-chain is more closely related to the embryonic $\pi$-chain than to the adult $\alpha^{\mathrm{A}}$-chain.

A comparison of the published sequences for the embryonic $\alpha$-chains from chicks, pigs, and humans with adult human hemoglobin and the $\mathrm{HbA}$ and $\mathrm{HbD}$ from chicks reveals consistent divergance of several residues at important functional domains (Table 10). All embryonic $\alpha$-chains have blocked, i.e., acetylated, $\mathrm{NH}_{2}$-terminal amino groups, which abolishes the contribution of this site to the alkaline Bohr effect and reduces the oxygen-linked binding of chloride and carbon dioxide (110).

Nevertheless, the magnitude of the reduction of the Bohr effect of embryonic hemoglobins, which is close to zero, is not consistent with the proposed role of the $\mathrm{NH}_{2}$ terminus in adult hemoglobins, where blocking of these groups reduces the Bohr effect usually by $<50 \%$. Thus additional structural changes have to be involved.
TABLE 10. Comparison of published sequences of embryonic $\alpha$-chains

\begin{tabular}{rcccccc}
\hline \hline & Human $\alpha$ & $\alpha^{\mathrm{A}}$ & $\alpha^{\mathrm{D}}$ & $\pi$ & $\zeta$-Pig & $\zeta$-Human \\
\hline 20 & His & His & His & Gln & Gln & Gln \\
23 & Glu & Glu & Glu & Ser & Thr & Thr \\
38 & Thr & Ser & Gln & Gln & Gln & Gln \\
50 & His & His & Pro & Gln & Pro & Pro \\
82 & Ala & Lys & Glu & Lys & Lys & Lys \\
138 & Ser & Ala & Glu & Glu & Glu & Glu \\
Na1 & Val & Val & Met & $X$ - $\Lambda$ la & $X$-Ser & $X$-Ser \\
\hline
\end{tabular}

Some substitutions common to embryonic $\alpha$-chains from birds and mammals compared with human $\alpha$-chain and the $\alpha$-chains of chick hemoglobin A and $\mathrm{D}$. Na1, site of Bohr effect and $\mathrm{CO}_{2^{-}}$and chloride-binding site; $\alpha 20$ and $\alpha 50$, residues involved in external salt bridges to Glu $\alpha 23$ and Glu $\alpha 30$, respectively; $\alpha 38$, important $\alpha_{1} / \beta_{2}$ contact in oxy- and deoxyhemoglobin. $\alpha 138$ is adjacent to $\mathrm{COOH}$-terminal HC region. Data for $\alpha^{\mathrm{A}} / \alpha^{\mathrm{D}}$ from Schnek et al. (116) and Dodgson et al. (55); for chicken $\pi$-chain from Engel et al. (58); for pig $\zeta$-chain from Weber et al. (135); for human $\zeta$-chain from Clegg and Gagnon (47). [Modified from Clegg and Gagnon (47).]

At the sliding contact $\alpha_{1} \beta_{2}$, one finds a replacement of serine or threonine (human $\mathrm{HbA}$ and chick $\mathrm{HbA}$ ) by glutamine not only in all embryonic $\alpha$-chains but also in all $\alpha^{\mathrm{D}}$-chain sequences published so far (116). It has been suggested that this replacement may in part account for the higher intrinsic oxygen affinity of all embryonic hemoglobins; the fact that the intrinsic oxygen affinity of avian $\mathrm{HbD}$ is also in general higher than that of $\mathrm{HbA}$ supports this idea.

Two residues that allow the formation of stabilizing external salt bridges in adult $\alpha$-chains are also missing in the embryonic $\alpha$-chains. These are $\alpha 20$ His (which is replaced by glutamine) and $\alpha 50$ His (which is replaced by either proline or glutamine); this substitution is also found in all $\alpha^{\mathrm{D}}$-sequences.

Finally, all embryonic hemoglobins and all $\alpha^{\mathrm{D}}-$ chains share an unusual substitution in the $\mathrm{COOH}$-terminal region at position $\mathrm{H} 21$, where neutral amino acids (serine in human $\mathrm{HbA}$ and alanine in chick $\mathrm{HbA}$ ) are invariably replaced by glutamic acid. It is likely that replacement of a neutral by a charged residue in this crucial region significantly disturbs the tertiary structure of the $\mathrm{COOH}$ terminus as well as that of the $\mathrm{NH}_{2}$ terminus of the adjacent $\alpha$-chain, which may be relevant for the creation of intermolecular contact sites necessary for the aggregation of $\mathrm{HbD}$ and embryonic hemoglobin (see sect. IIIC). In addition, the $\pi$-chain has an unusually large number of substitutions at the $\alpha_{1} \beta_{1}$-interface where 11 amino acids are exchanged compared with the adult $\alpha^{\mathrm{A}}$-chain; this may have resulted in a different packing of the subunits compared with adult hemoglobin and may have consequences both for the Bohr effect and for the affinity for organic phosphates.

\section{B. Red Blood Cell Organic Phosphate Pattern}

All avian embryos progress through rather complicated changes of their red blood cell organic phosphate 
metabolism $(5,27,76)$, and the ontogenetic pattern is remarkably consistent, as demonstrated by comparative investigations $(4,77)$. During the first part of development ATP is the principal organic phosphate both of the primitive and the emerging definitive red blood cells $(4,16)$. Between days 4 and 7 peak concentrations of ATP are found, resulting in a stoichiometric ratio of ATP to $\mathrm{Hb}$ of $\geq 5: 1$, corresponding to $\sim 17-20 \mathrm{mmol}$ ATP/ $\mathrm{kgH}_{2} \mathrm{O}$. From day 7 the ATP concentrations gradually decline until day 14 of development. At this stage there is a rapid drop of ATP matched by a concomitant increase of 2,3-DPG (76).

The potency of organic phosphates to decrease the oxygen affinity of both adult and embryonic chick hemoglobins is such that $\mathrm{IP}_{5}>\mathrm{IP}_{4}>>\mathrm{ATP}>2,3-\mathrm{DPG}$, which explains why substitution of ATP by an equimolar amount of 2,3-DPG causes an increase of hemoglobin oxygen affinity $(16,27)$.

The binding sites for organic phosphates are identical in both embryonic and adult chick hemoglobin except for the fact that one site involved in the binding of $\operatorname{IP}_{5}(\beta 135 \mathrm{Arg})$ is replaced by Asn in the $\epsilon$-chain and by Ser in the $\rho$-chain (39). The consistently lower effect of organic phosphate on embryonic hemoglobin phosphate compared with $\mathrm{HbA}$ therefore cannot be attributed to direct changes in the amino acid composition of the binding site but may result from a general rearrangement of the subunits caused by the large number of exchanges at the $\alpha_{1} \beta_{1}$ contact (39).

Nevertheless, the affinity of avian embryonic hemoglobin for organic phosphates is quite high, and it is therefore puzzling why ATP is present in such excessively high concentrations in the early embryonic red blood cells.

There are indications that such high concentrations may have a significant influence on the regulation of the Donnan equilibrium. Direct measurements of the distribution of chloride ions have shown that they follow the Donnan distribution in early embryonic red blood cells (12) such that under physiological conditions the distribution ratio $\mathrm{r}=\mathrm{Cl}_{\mathrm{i}} / \mathrm{Cl}_{\mathrm{e}}$ is 0.6 (where subscripts $\mathrm{i}$ and e represent intracellular and extracellular, respectively). Although in human red blood cells hemoglobin is the major source of impermeable anion (cf. Ref. 57), this does not hold for the embryonic hemoglobins, which have high isoelectric points ( $\mathrm{pI}$ for $\mathrm{HbP}=8.1$ at $20^{\circ} \mathrm{C}$ ) and in addition a much lower buffer capacity due to the decreased histidine content of both the embryonic $\alpha$ and $\beta$-chains $(38,39)$.

Consequently the buffer power $\beta$ is only $4.6 \mathrm{~mol} \mathrm{H}^{+}$/ mol $\mathrm{Hb}_{4}$ in the range of $\mathrm{pH}$ 7-8 compared with $9.3 \mathrm{~mol}$ for chick $\mathrm{HbA}$ and $7.3 \mathrm{~mol}$ for $\mathrm{HbD}$. At physiological intracellular $\mathrm{pH}$ of 7.2-7.4, embryonic hemoglobin will bear a slight positive charge of $<5 \mathrm{mmol} / \mathrm{kgH}_{2} \mathrm{O}$ ( $\mathrm{R}$. Baumann and E. A. Haller, unpublished observation). Using the data of Duhm (57) for the dissociation constant of ATP at physiological $\mathrm{pH}$, one calculates a net anionic charge of $\sim 78 \mathrm{mmol} / \mathrm{l} \mathrm{H}_{2} \mathrm{O}$, which together with the osmotic contribution explains the chloride distribution ratio. Because of the low buffer power of embryonic hemoglobin, it is also reasonable to assume that ATP and not hemoglobin is the predominant intracellular buffer of early embryonic red blood cells. High concentrations of organic phosphates (ATP or 2,3-DPG) have also been demonstrated for the embryonic red blood cells of some mammalian species $(63,78)$, and although much less is known about the charge properties of the mammalian embryonic hemoglobins, published sequences show that they also are characterized by a notably low content of histidine compared with adult hemoglobin.

\section{Influence of Organic Phosphates on Aggregation of Hemoglobin $P$ and Hemoglobin $D$}

In 1974 Morrow et al. (100) observed that chick HbD rapidly crystallized when deoxygenated at room temperature. This process was reversed by oxygenation and inhibited by increased ionic strength. These results were subsequently extended to $\mathrm{HbD}$ from other species as well (13), and it could be shown that the binding of the organic phosphate cofactors, namely, ATP and $\mathrm{IP}_{6}$, increases solubility substantially; similarly, addition of chick HbA (but not human $\mathrm{HbA}$ ) increased solubility. Corresponding observations were made with purified hemolysates from 6-day chick embryo. Again solubility of the deoxygenated sample was very low but increased to the physiological range in the presence of organic phosphates.

Thus organic phosphates not only regulate oxygen affinity but are apparently also necessary for maintenance of adequate solubility of embryonic hemoglobin. This is especially pertinent in view of the fact that hemoglobin oxygen saturation may be as low as $10 \%$ (or less) in the venous part of the intraembryonic circulation. The regulation of hemoglobin solubility by organic phosphates may also explain why in contrast to several mammalian fetuses, where the oxygen affinity of fetal blood is increased by reducing the intracellular concentration of ATP or 2,3-DPG to very low values (cf. Ref. 32 ), this strategy is never employed by avian embryos. Here changes of hemoglobin oxygen affinity are caused by changes in the red blood cell organic phosphate pattern (76). Because the allosteric effectivity is different for ATP, 2,3-DPG, and inositolphosphate, substitution of one effector, for example, ATP, by either a less potent (2,3-DPG) or a much stronger $\left(\mathrm{IP}_{5}\right)$ effector molecule will automatically cause an increase or a decrease of hemoglobin oxygen affinity.

Further investigations were carried out to establish the presence or absence of hemoglobin aggregates composed of several tetramers by measuring the colloid osmotic pressure of solutions of $\mathrm{HbA}, \mathrm{HbD}$, purified $\mathrm{HbP}$, and fresh hemolysate of red blood cells from 6-day embryos. These data demonstrated that both oxy- and deoxy-HbD as well as $\mathrm{HbP}$ form aggregates composed of at least two to three tetramers under physiological conditions (14). However, no difference could be observed in the aggregation status of oxygenated or deoxygenated 
solutions at physiological hemoglobin concentrations; likewise there was no difference in the aggregation behavior of purified $\mathrm{HbP}$ compared with fresh hemolysate despite the fact that hemoglobin oxygen affinity and cooperativity are markedly different. The oxygen equilibrium data show that unpurified hemolysate from primitive red blood cells has a saturation-dependent change of cooperativity, with $n>4$ in the upper saturation range, and in addition the oxygen affinity is significantly lower than that of a purified solution of $\mathrm{HbP}$ to which identical amounts of ATP were added. Also the latter specimen had normal cooperativity, with $n$ well below 4 throughout $(14,16)$.

Thus, irrespective of the oxygenation state, both embryonic hemoglobin as well as $\mathrm{HbD}$ can exist as stable compounds composed of several tetramers under physiological conditions. This rules out ligand-linked association-dissociation phenomena as the principal cause for elevated cooperativity, as is indeed indicated by the normal oxygenation properties of both $\mathrm{HbD}$ and $\mathrm{HbP}$ when analyzed under controlled conditions, i.e., in the presence of ATP and chloride as allosteric effectors $(11,16)$.

Nevertheless, the aggregation creates the possibility that cooperativity can be altered via binding of yet another effector molecule that associates with the aggregate in a ligand-dependent manner.

As adult $\mathrm{HbD}$ as well as $\mathrm{HbA}$ share the same $\beta$ chain, it is reasonable to assume that the sites responsible for the aggregation reside on the $\alpha$-chain of $\mathrm{HbD}$ and on the $\pi$-chain of embryonic $\mathrm{HbP}$.

From the structural information available one substitution that is uniformly shared by all embryonic $\alpha$ chains and $\alpha^{\mathrm{D}}$-chains is the introduction of the negatively charged glutamic acid residue at position 138, which due to its location close to the structurally extremely important $\mathrm{COOH}$-terminal region must create significant perturbations. Clearly it would be desirable to analyze this point by methods yielding more direct information about the three-dimensional arrangement of this domain.

Nevertheless, even in the absence of this information the functional neccessity to maintain the sites for intermolecular aggregation must have created a substantial structural constraint, explaining perhaps in part why there exists such a pronounced homology between the embryonic $\alpha$-chains of various vertebrate species and classes (49).

\section{Oxygen-Binding Properties of Embryonic Blood Between Days 3-8 of Development}

Although the oxygen affinity of isolated embryonic chick hemoglobins is high (even in the presence of excess concentrations of ATP), measurements of embryonic blood oxygen affinity performed at a stage when predominantly primitive red blood cells are present invariably demonstrated that the blood oxygen affinity is much lower than expected. This was first observed by Faroqui and Huehns (60), who measured oxygen binding to chick embryo red blood cells suspended in phosphate buffer $\mathrm{pH} 7.13$ from day 3 onward. They found a rapid increase of $\mathrm{P}_{50}$ to values exceeding those for adult blood, and they noted that the slope of the oxygen equilibrium curve at day 7 was biphasic. Subsequent measurements were carried out under conditions more closely approaching the physiological state. Lapennas and Reeves (82) used their thin-film method to determine the oxygen-binding properties of embryonic blood from 4 days of development onward.

They equilibrated the blood with the $\mathrm{PCO}_{2}$ of the air cell to achieve conditions similar to those in the vitelline vein or chorioallantoic vein but did not measure actual $\mathrm{pH}$.

Their study demonstrated a decrease of the oxygen affinity between days 4 and 6 when $\mathrm{P}_{50}$ was found to increase from $\sim 38$ to 49 Torr, and they observed a continuous saturation-dependent increase of the $n$ value of the oxygen-binding curve of primitive red blood cells from $n=1$ to $\sim 6.5$ in the upper saturation range.

Our own data were recorded on red blood cell suspensions equilibrated with buffer solutions of $\mathrm{pH}$ 7.4$8.1(16,17,91,92)$. The $\mathrm{P}_{50}$ values obtained from these measurements when related to the physiological $\mathrm{pH}$ of the vitelline vein at days 4 and 6 , respectively, are 40 and 52 Torr, which is in good agreement with the abovementioned results. When compared at constant $\mathrm{pH}$ of $7.75, \mathrm{P}_{50}$ increased from 46.5 Torr at day 3 to 62.2 Torr at day 6 . We also observed a strong saturation dependence of the $n$ value, with maximal $n$ value $\left(n_{\max }\right)>7$ in the upper saturation range. Because Lapennas and Reeves (82) kept $\mathrm{PCO}_{2}$ rather than $\mathrm{pH}$ constant in their measurements and because $\mathrm{pH}$ decreases with increasing oxygen saturation, this technique tends to underestimate the apparent $n$ value. This explains the difference between $n_{\max }$ in the two sets of data. With regard to the Bohr effect, from day 4 to 6 there is a substantial change of the Bohr effect $\left(\Delta \log \mathrm{Po}_{2} / \Delta \mathrm{pH}\right)$. At day 4 it is absent in the low saturation range, i.e., at oxygen saturations of $<30 \%, \Delta \log \mathrm{PO}_{2} / \Delta \mathrm{pH}=0$, and it increases slowly with increasing oxygen saturation to a maximum value of -0.30 at $80 \%$ saturation. At day 6 the Bohr effect is present over the whole oxygen saturation range and increased to about -0.50 at oxygen saturation $>20 \%$ (16).

The above-mentioned results obtained in red blood cell suspensions and in whole blood differ in several parts from those obtained in purified solutions either with the separated hemoglobins or total hemolysate. In the first place, the results obtained in purified hemoglobin solutions never gave $n$ values $>3$; moreover, when the oxygen affinity at $\mathrm{P}_{50}$ is compared under conditions where the hemoglobin concentration and buffer $\mathrm{pH}$, as well as ATP concentration, all mimic physiological conditions, there remains a substantial difference between the $\mathrm{P}_{50}$ in solution and in cells, which amounts to $>20$ Torr when data are compared at $\mathrm{pH}$ 7.2-7.4 (16).

Likewise, there is as yet no explanation for the drastic changes of the Bohr effect of whole blood between days 4 and 6 . The in vitro results demonstrate that the Bohr effect is substantially increased by ATP, 
but the marginal ATP concentration changes between days 4 and 6 cannot account for the changes of the Bohr effect. When unstripped freshly prepared hemolysate is investigated the resulting oxygen equilibrium, as well as the Bohr effect, mimies the results obtained for embryonic red blood cells (16). In other words, the available experimental evidence strongly suggests that additional factors are involved in the regulation of the oxygenbinding properties of the early embryonic red blood cells.

In mammalian embryos such a clear-cut increase of the $n$ value to $>4$ has recently been demonstrated for embryos from the marsupial tammar wallaby (73). In addition, published oxygen equilibrium curves for embryonic rat blood and embryonic mouse blood also indicate a marked nonlinearity of the oxygen equilibrium curve, with $n$ approaching 4 in the upper saturation range $(29,63,105)$.

\section{Effect of replacement of definitive red blood cells on embryonic blood oxygen affinity}

From day 6 of incubation definitive red blood cells enter the circulation of the chick embryo, and by day 8 of development $\sim 75 \%$ of all circulating red blood cells belong to the definitive population (19). The life span of the first populations of definitive red blood cells is short, i.e., $<1 \mathrm{wk}$, and there is a rapid expansion of the total red blood cell volume by a factor of 10 between days 7 and 1.4 .

As the definitive red blood cells usually enter the circulation after their terminal mitosis, this expansion is almost entirely due to rapid influx of cells from the extravascular erythropoietic sites in the yolk sac and in the intraembryonic mesoderm. When one analyzes the whole blood oxygen affinity at fixed extracellular $\mathrm{pH}$ one sees that between days 6 and 8 of development there is very little change of the oxygen affinity measured as $\mathrm{P}_{50}$, and furthermore the $n$ value still remains elevated above 4, although not as high as in blood containing only primitive red blood cells $(17,82)$. After day 8 there is a substantial increase of the hemoglobin oxygen affinity. One may therefore ask if these changes are due predominantly to replacement of primitive red blood cells or if there are changes within the definitive red blood cell population. As the most immature red blood cells are always those with the lowest hemoglobin concentration and lowest density, red blood cells can be fractionated according to their age using density gradient centrifugation, since mature red blood cells will be in the bottom fractions. When the oxygen-binding curves of immature definitive red blood cells were analyzed as a function of age it was found that their $\mathrm{P}_{50}$ decreased from 85.3 Torr (pH 7.4, day 7) to 59.6 Torr at day 14, whereas in an older fraction the corresponding changes were from 80 to 55 Torr (11).

Thus the major part of the oxygen affinity change occurs within the definitive red blood cell population per se. This is also evident from a comparison of the oxygen- binding curves of young definitive red blood cells from day 7 with cells from day 6 (95\% primitive). There was hardly any difference between both curves except that the data for definitive red blood cells indicated that cooperativity is slightly decreased in the upper saturation range compared with primitive red blood cells but still $n$ is $>4$ (11).

Thus, although both cell types contain a different set of hemoglobins, this initially has no functional consequence whatsoever. However, compared with adult blood there is one significant difference with regard to the relative amount of $\mathrm{HbA}$ and $\mathrm{HbD}$ inside the cell. In adult chicks the ratio of $\mathrm{HbA}$ to $\mathrm{HbD}$ is $\sim 3: 1$, whereas at day 7 of incubation it is $\sim 0.64: 1$ and increases to 1.05 at day 9 (17). Thus in this transitional period $\mathrm{HbD}$ rather than $\mathrm{HbA}$ is the major adult hemoglobin component, and consequently the intracellular concentration of $\mathrm{HbD}$ is high enough to result in the formation of stable aggregates. Other avian species show the same developmental pattern for adult hemoglobin synthesis $(41,123)$. However, the oxygen-binding curve of concentrated (200 $\mathrm{g} \mathrm{Hb} / \mathrm{l}) \mathrm{HbD}$ solutions in the presence of physiological amounts of ATP does not display saturation dependence of cooperativity or $n$ values $>4(11,12)$. It therefore seems possible that regulation of the in vivo oxygen affinity of both primitive and early definitive red blood cells (i.e., up to day $9 / 10$ ) involves a common but as yet unidentified allosteric effector that either disappears or becomes too low in concentration during later stages of development to have an effect.

The large changes of both oxygen affinity and cooperativity seen between days 8 and 14 have several causes; the best understood is certainly the gradual fall of the red blood cell ATP concentration (4), whereas the contributions made by the reduction of intracellular $\mathrm{HbD}$ in conjunction with the missing effector have to await further experimental analysis.

In conclusion, however, it seems as if $\mathrm{HbD}$ plays a major role during embryonic development as a transitory hemoglobin, which because of the greater flexibility of funtional regulation (compared with either embryonic or adult $\mathrm{Hb}$ ) allows a smooth transition from primitive to definitive erythropoiesis. In this context it would be interesting to see if those avian species that as adults possess no HbD express HbD during embryonic development.

\section{E. Calculation of In Situ Blood Oxygen Saturation and Content in Various Parts of Embryonic Circulation}

Oxygen hemoglobin equilibrium curves for different $\mathrm{pH}$ values covering the physiological $\mathrm{pH}$ range and the $\mathrm{PO}_{2}$ values of the early embryonic blood in ovo have been determined by Baumann and co-workers $(16,17)$. Using the Bohr coefficients obtained from the oxygen equilibrium curves, we interpolated the equilibrium measurements at actual $\mathrm{pH}$ for the blood of the vitelline vein, the vitelline artery, and the jugular vein (Fig. 9). The actual oxygen saturation of the blood was estimated 

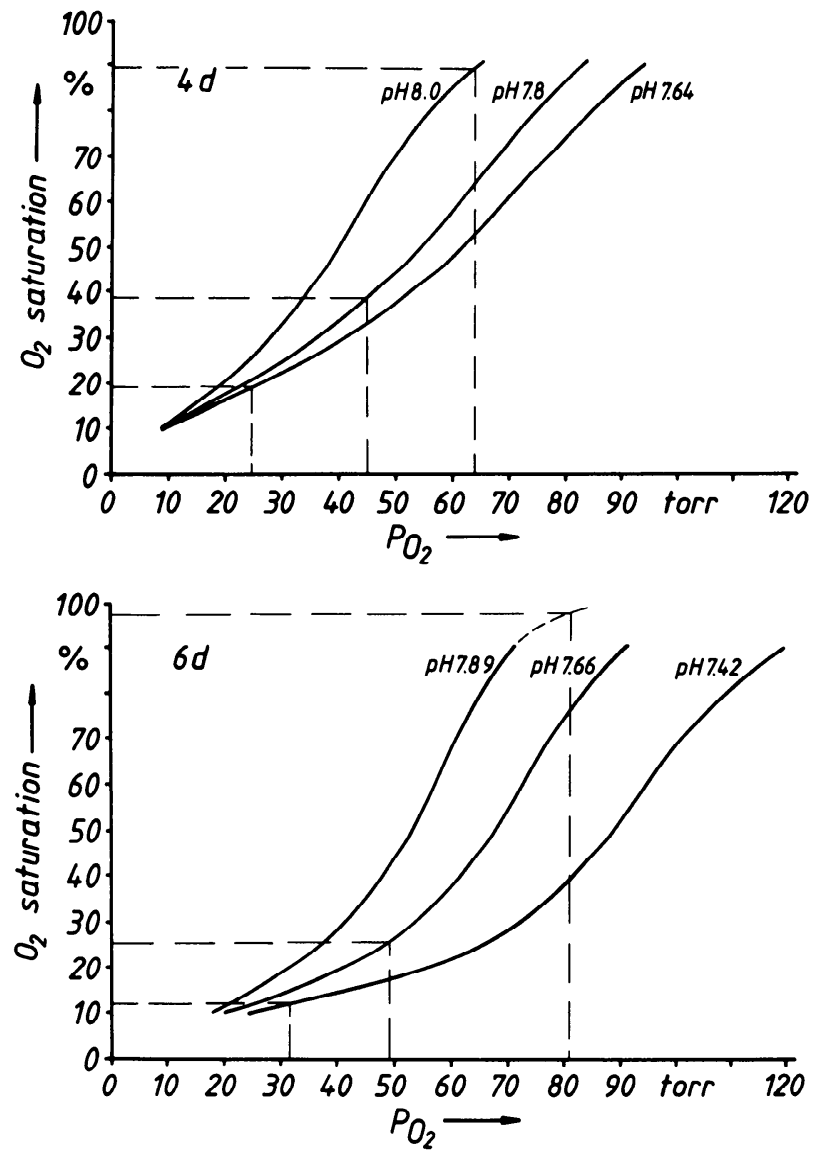

FIG. 9. Oxygen equilibrium curves of blood of 4- and 6-day-old chick embryos at actual $\mathrm{pH}$. Curves refer to blood of vitelline vein, vitelline artery, and jugular vein (from left to right). [From Meuer et al. (96).]

from these curves using the measured intravascular $\mathrm{PO}_{2}$ (96). The results are summarized in Table 11.

The venous-to-arterial difference in oxygen saturation between vitelline vein and vitelline artery is $52 \%$ at day 4 and $\sim 70 \%$ at day 6 , which results in respective arterial oxygen saturations of 37 and $25 \%$. Compared with the adult animal these values are extremely low. When the blood passes through the intraembryonic circulation, oxygen saturation is further reduced by $\sim 15 \%$ of saturation, yielding a venous saturation of as low as $12 \%$ at day 6 . This extreme extraction of oxygen is only possible because the arterial $\mathrm{PO}_{2}$ is fairly high (between 45 and 49 Torr) and tissue $\mathrm{Po}_{2}$ is near 0 Torr, demonstrating that tissue oxygenation depends critically not only on oxygen availability but also on the low oxygen affinity of the blood and a large Bohr effect.

Because of the low hemoglobin concentration of the blood of early embryos, the oxygen content of the blood offered to the embryo proper (remember that data for the vitelline artery are identical with those of the dorsal aorta) is no more than $1.4 \mu \mathrm{l} / 100 \mu \mathrm{l}$ at day 6 and even less at day 4. About $10 \%$ of the arteriovenous difference in oxygen content (see Table 11) is covered by physically dissolved oxygen. Moreover, the oxygen equilibrium curve is more or less a straight line when related to

actual acid-base conditions. In other words, there is a direct linear relationship between changes in intravascular $\mathrm{Po}_{2}$ and oxygen release $\left(\Delta \mu \mathrm{O}_{2} / \Delta \mathrm{Po}_{2}\right)$ from embryonic blood.

The principal effect of the higher cooperativity of oxygen binding to embryonic hemoglobins is not to safeguard oxygen content but to maintain a fairly high $\mathrm{Po}_{2}$ after mixing in the heart. Using the data for the oxygen affinity and Bohr effect of adult chicken blood (7), we calculated the $\mathrm{PO}_{2}$ of the dorsal aorta for the $\mathrm{pH}$ and oxygen saturation values that are actually present. These results show that if chick embryos had blood with adult properties the $\mathrm{PO}_{2}$ in the dorsal aorta would drop to 16 Torr at day 4 and 24 Torr at day $6(9)$. Thus the high cooperativity of embryonic blood results in a net gain for the $\mathrm{PO}_{2}$ of the intraembryonic arterial blood of $\sim 25-$ 30 Torr.

TABLE 11. $\mathrm{Po}_{2}, p H$, oxygen saturation, and oxygen content of the blood in intra- and extraembryonic vessels

\begin{tabular}{lll}
\hline & Day 4 & Day 6 \\
\hline$[\mathrm{Hb}], \mathrm{g} / \mathrm{l}$ & 20 & 35 \\
$\mathrm{O}_{2}$ capacity, $\mathrm{ml}(\mathrm{STP}) / \mathrm{l}$ & 27.2 & 47.6
\end{tabular}

Vitelline vein

$\mathrm{PO}_{2}$, Torr

Saturation, \%

$\left[\mathrm{HbO}_{2}\right], \mathrm{ml} / \mathrm{l}$

$\left[\mathrm{O}_{2}\right]_{\text {diss }}, \mathrm{ml} / \mathrm{l}$

Total $\left[\mathrm{O}_{2}\right], \mathrm{ml} /$

$\mathrm{PO}_{2}$, Torr

$\mathrm{pH}$

Saturation, \%

$\left[\mathrm{HbO}_{2}\right], \mathrm{ml} / \mathrm{l}$

$\left[\mathrm{O}_{2}\right]_{\text {diss }}, \mathrm{ml} / \mathrm{l}$

Total $\left[\mathrm{O}_{2}\right], \mathrm{ml} / \mathrm{l}$

64

8.00

89

24.2

2.1

26.3

Vitelline artery

45
7.80
37
10.1
1.5
11.6

13.5

\section{Jugular vein}

$\mathrm{PO}_{2}$, Torr

$\mathrm{pH}$

Saturation, \%

$\left[\mathrm{HbO}_{2}\right], \mathrm{ml} / \mathrm{l}$

$\left[\mathrm{O}_{2}\right]_{\text {diss }}, \mathrm{ml} / \mathrm{l}$

Total $\left[\mathrm{O}_{2}\right], \mathrm{ml} / \mathrm{l}$

$\mathrm{VADO}_{2}, \mathrm{ml} / \mathrm{l}$

Physically dissolved, \%

$\mathrm{AVDO}_{2}, \mathrm{ml} / \mathrm{l}$

Physically dissolved, \%

29
7.64
22
6.0
0.96
6.96
14.7
4.1
4.6
11.7

32

7.42

12

5.7

1.1

6.8

$>34.4$

$<3.2$

6.7

8.2
Hemoglobin concentration [Hb] was taken from Refs. 17 and 111. Oxygen saturation was determined from oxygen hemoglobin equilibrium curves (Fig. 9) and measured mean $\mathrm{Po}_{2}$ values (92). Hüfner number, $1.36 \mathrm{ml} \mathrm{O}_{2} \mathrm{STP} / \mathrm{g} \mathrm{Hb}$, was used to calculate the concentration of oxygen bound to hemoglobin at $100 \%$ saturation (oxygen capacity). For the solubility coefficient of oxygen in blood the value $0.033 \mathrm{ml} \mathrm{O}_{2}$ STP/1 Torr determined for water at $38^{\circ} \mathrm{C}(67)$ was taken. Total oxygen content (total $\left[\mathrm{O}_{2}\right]$ ) is the sum of oxygen bound to hemoglobin $\left(\left[\mathrm{HbO}_{2}\right]\right)$ and physically dissolved oxygen $\left(\left[\mathrm{O}_{2}\right]_{\text {diss }}\right)$. $\mathrm{VADO}_{2}$ and $\mathrm{AVDO}_{2}$ are the differences in total oxygen content between vitelline vein and vitelline artery and between vitelline artery and jugular vein, respectively. 
The working range of the oxygen saturation curve utilized for the supply to the embryo proper and those parts of the extraembryonic circulation that may depend on the vitelline artery is the lower part of the oxygen equilibrium curve where cooperativity approaches $n=1$. The fact that the relationship between $\mathrm{PO}_{2}$ and blood oxygen content is almost invariant between days 4 and 6 suggests that the $\mathrm{PO}_{2}$ gradients themselves are subject to tight regulation. Furthermore, the data make it abundantly clear that any derangement of the oxygen supply to the embryo proper automatically endangers embryonic survival, since there is no oxygen "reserve" present in the embryo as oxygen contents range from at most $2 \mu \mathrm{l} / 100 \mu \mathrm{l}$ blood to $<1 \mu \mathrm{l} / 100 \mu \mathrm{l}$ blood. Thus the principal function of the early embryonic hemoglobin seems to be less one of oxygen transporter with high oxygen-carrying capacity but rather its presence helps to create and maintain $\mathrm{Po}_{2}$ gradients inside the embryo that guarantee adequate supply. As it is the lower part of the oxygen equilibrium curve that is used for the oxygen supply of the embryo proper, the absence of a large Bohr effect in this saturation range guarantees that within certain limits oxygen supply will not be affected by local changes in $\mathrm{pH}$.

\section{F. Estimation of Intraembryonic Oxygen Transport Rates}

The total oxygen uptake of the egg that has been repeatedly determined $(61,72,113)$ is not an adequate measure of the embryonic oxygen uptake, since a substantial amount is required to supply the extraembryonic structures (2). With the use of Fick's principle the embryonic oxygen uptake rate can be determined either from the intraembryonic venous flow or the extraembryonic blood flow. Blood flow data for early chick embryos were reported first by Clark and $\mathrm{Hu}(46)$ and by Stewart et al. (122). Both groups determined blood flow velocity of the dorsal aorta using a pulsed Doppler meter. A summary of blood flow and blood pressure measurements in 2- to 6-day-old chick embryos is given by $\mathrm{Hu}$ and Clark (74). Wispé et al. (136) studied the change of dorsal aortic blood flow in hypothermia. Because the dorsal aorta not only supplies embryonic tissue but also the extraembryonic circulation, it is impossible to estimate intraembryonic venous or extraembryonic blood flow from the dorsal aorta blood flow. Therefore we determined the total extraembryonic blood flow by a different method.

\section{Determination of extraembryonic blood flow}

Because of the small blood vessels of the yolk sac vasculature, volumetric blood flow was assessed by measuring the velocity of circulating fluorescent-labeled blood cells using the video frame-by-frame method (Meuer, unpublished observations). From mean blood cell velocity and vessel diameter the mean blood
TABLE 12. Mean total blood flow in yolk sac circulation of 4- and 6-day-old chick embryos and calculation of cardiac output and embryonic oxygen uptake rate

\begin{tabular}{lcc}
\hline \hline & Day 4 & Day 6 \\
\hline Extraembryonic blood flow, $\mu \mathrm{l} / \mathrm{s}$ & $0.66 \pm 0.22$ & $1.2 \pm 0.41$ \\
Percentage of cardiac output, \% & 23 & 16 \\
Calculated cardiac output, $\mu \mathrm{l} / \mathrm{s}$ & 2.9 & 7.4 \\
Dorsal aortic blood flow, $\mu \mathrm{l} / \mathrm{s}$ & 1.14 & 3.56 \\
VADO, $\mathrm{ml} / 1$ & 14.7 & 34.4 \\
Embryonic $\mathrm{O}_{2}$ uptake, nl (STPD)/s & 9.6 & 40.2 \\
Total egg $\mathrm{O}_{2}$ uptake, $\mu \mathrm{l}(\mathrm{STPD}) / \mathrm{min}$ & 7 & 20 \\
Sp. embryonic $\mathrm{O}_{2}$ uptake, \% & 8 & 12 \\
\hline
\end{tabular}

Extraembryonic blood flow data are means \pm SD. The percentage of extraembryonic venous blood flow on cardiac output was previously calculated from the oxygen saturation of intra- and extraembryonic blood (92). Dorsal aortic blood flow was taken from Zahka et al. (139). $\mathrm{VADO}_{2}$, vitelline venous-to-arterial difference of oxygen concentration of blood (see sect. III $E$ ); sp. embryonic oxygen uptake, percentage of specific embryonic oxygen uptake on total egg oxygen uptake. Values for total egg $\mathrm{O}_{2}$ uptake were taken from Freeman and Vince (61).

flow was calculated (140). Summarizing the blood flow of all veins entering the embryo gave the total extraembryonic blood flow.

Mean total extraembryonic blood flow was found to be $0.66 \mu \mathrm{l} / \mathrm{s}$ at $d a y$ 4, increasing nearly twofold by day 6 . From these data and the estimated percentage of blood flow of the vitelline veins as percent total blood flow into the heart (92) one calculates a cardiac output of 2.9 $\mu \mathrm{l} / \mathrm{s}$ at day 4, which increases 2.5 -fold by day 6 (Table 12).

Clark and $\mathrm{Hu}(46)$ determined a mean blood flow in the dorsal aorta of $0.77 \mu \mathrm{l} / \mathrm{s}$ at day 4. Zahka et al. (139) reported values of $1.14 \mu \mathrm{l} / \mathrm{s}$ at day 4 and $3.56 \mu \mathrm{l} / \mathrm{s}$ at day 6 , and $\mathrm{Hu}$ and Clark (74) reported values of 0.85 and 2.4 $\mu \mathrm{l} / \mathrm{s}$ at days 4 and 6 , respectively.

Because the dorsal aorta does not only supply the yolk sac circulation via the vitelline arteries but also the allantoic circulation via the umbilical arteries and furthermore supports the trunk of the embryo, it was expected that the dorsal aorta blood flow would be higher than the blood flow through the yolk sac circulation. On the other hand, the dorsal aorta blood flow underestimates cardiac output, because the dorsal aorta does not supply the head of the embryo. Estimations of the share of blood flow to the head on cardiac output revealed values of $<10 \%$ (74). If this is true, the cardiac output calculated from our measurements is about twice as high as the respective value estimated from dorsal aorta blood flow.

\section{Embryonic oxygen uptake rate}

From the extraembryonic blood flow and the venous-to-arterial differences in oxygen saturation one calculates embryonic oxygen uptake rates of 9.6 and 40.2 $\mathrm{nl} / \mathrm{s}$ at 4 and 6 days, respectively. These numbers are only $\sim 10 \%$ of the total oxygen upake of the egg, which 
TABLE 13. Mean $\mathrm{PO}_{2}$ in vitelline blood vessels of 4- and 6-day-old chick embryos incubated in normoxic and hypoxic environments

\begin{tabular}{llllll}
\hline \hline & \multicolumn{4}{c}{$\mathrm{Po}_{2}$, Torr } \\
\cline { 2 - 3 } \cline { 5 - 6 } \cline { 5 - 6 } Location & \multicolumn{2}{c}{ Normoxia } & & \multicolumn{2}{c}{ Hypoxia } \\
\cline { 2 - 6 } \cline { 5 - 6 } & Day 4 & Day 6 & & Day 4 & Day 6 \\
\hline Vitelline arteries & $45 \pm 5$ & $49 \pm 6$ & & $45 \pm 6$ & $46 \pm 9$ \\
Vitelline veins & $64 \pm 10$ & $81 \pm 12$ & & $59 \pm 8^{*}$ & $61 \pm 10^{*}$ \\
\hline
\end{tabular}

Values are means \pm SD. Eggs were either incubated in air (mean ambient $\mathrm{Po}_{2}=150$ Torr) or in a hypoxic gas mixture (mean ambient $\mathrm{PO}_{2}=100$ Torr). Measurements were performed in the same ambient gas composition. * Significant differences $(P<0.05)$ between hypoxia and normoxia.

demonstrates that in the early embryo the major part of the total oxygen uptake is utilized by the extraembryonic structures. The data also show that the percentage of embryonic oxygen consumption tends to increase with increasing age. This is consistent with the finding of Ar et al. (2), who reported that the percentage of embryonic oxygen utilization is $69 \%$ at day 12 and increases up to $94 \%$ by day 20 .

\section{ADAPTIVE CHANGES OF OXYGEN TRANSPORT AND} RED BLOOD CELL DEVELOPMENT DURING EXPOSURE TO SHORT-TERM AND CHRONIC HYPOXIA

It has been repeatedly shown that embryonic growth and development is strongly influenced by oxygen availability. In general, exposure to hypoxia causes retarded development $(17,18,112,132)$, increased mortality, and a fall in the embryonic respiratory rate $(18,132)$.

Conversely, exposure to elevated ambient $\mathrm{PO}_{2}$ accelerates growth rate and rate of oxygen consumption of early as well as late chick embryos $(3,89)$. Thus available experimental evidence indicates that up to a point the embryo can adjust its metabolic rate to changes in oxygen availability. It is important to know how this is effected and to which extent the embryo is able to adapt to oxygen deficiency. Results demonstrating adaptive changes of blood gas transport properties are presented next.

\section{A. Effect of Hypoxia on Oxygen Pressure in Embryonic Circulation}

The $\mathrm{PO}_{2}$ in the vitelline blood vessels of chick embryos incubated in moderate hypoxia $\left(13.5 \% \mathrm{O}_{2}-86.5 \%\right.$ $\mathrm{N}_{2}$ ) was determined by Meuer and Baumann (91). Table 13 compares the results with the blood $\mathrm{Po}_{2}$ measured in normoxic incubated embryos.

As expected, the $\mathrm{PO}_{2}$ in the vitelline veins that collect the blood from the extraembryonic gas exchange vessels is lower in hypoxia than in normoxia. Surpris- ingly in hypoxic incubation the arterial $\mathrm{Po}_{2}$ values do not differ significantly from the normoxic group. It has been shown that the vitelline arterial $\mathrm{Po}_{2}$ is approximately equal to the intraembryonic arterial $\mathrm{Po}_{2}$ (92). Furthermore, it is very likely that tissue $\mathrm{PO}_{2}$ values in hypoxia are also close to zero, as in normoxic incubation (sect. IIC). This suggests that the $\mathrm{PO}_{2}$ difference between intraembryonic arterial blood and embryonic tissue that determines tissue oxygen uptake is the same in hypoxia and normoxia. On the other hand, the differences in embryonic dry weight between normoxia and hypoxia indicate a lower metabolic rate in hypoxic incubated embryos.

It is not known how the embryo adapts to reduced oxygen supply. The diminished metabolic rate could be due to several reasons: reduced capillary blood flow in hypoxia due to reduced cardiac output, diminished tissue vascularization, and/or reduced aerobic metabolic rate per unit tissue.

The measured data suggest that in early chick embryos an arterial $\mathrm{Po}_{2}$ of $\sim 45$ Torr is the lower limit tolerated by the embryo. Consequently, if hypoxia develops to an extent that cannot be countered by adaptive mechanisms, the embryo is no longer able to survive.

\section{B. Estimates of Blood Volume in Normoxia and Hypoxia}

The blood and red blood cell volumes of chick embryos exposed to experimental hypoxia $\left(13.5 \% \mathrm{O}_{2}\right)$ have been determined between days 4 and 8 of incubation (17, 117 ) to find out if hypoxia causes an adaptive expansion of blood and red blood cell volumes. Table 14 contains the results of these investigations. The total blood volume as well as the red blood cell volume of control and hypoxic embryos are not different until day 6 of development. At days 7 and 8 values for hypoxic embryos are lower than in the control group. This reflects the general retardation of the hypoxic embryos that becomes more prominent with increasing age. When blood volume is instead correlated with embryonic weight (to allow comparison at similar developmental stages) the difference is no longer observed (17).

In conclusion it can be said that during early development the chick embryo is unable to counter hypoxia by an increased production of red blood cells and/or ex-

TABLE 14. Blood and red blood cell volume in normoxic and hypoxic chick embryos

\begin{tabular}{|c|c|c|c|c|c|c|}
\hline \multirow{2}{*}{$\begin{array}{c}\text { Day of } \\
\text { Incubation }\end{array}$} & \multicolumn{2}{|c|}{$\begin{array}{c}\text { Total Blood } \\
\text { Volume, } \mu \mathrm{l}\end{array}$} & \multicolumn{2}{|c|}{$\begin{array}{l}\text { Total Red Blood } \\
\text { Cell Volume, } \mu \mathrm{l}\end{array}$} & \multicolumn{2}{|c|}{ Hematocrit } \\
\hline & Air & $13.5 \% \quad \mathrm{O}_{2}$ & Air & $13.5 \% \quad \mathrm{O}_{2}$ & Air & $13.5 \% \quad \mathrm{O}_{2}$ \\
\hline 4 & 50.0 & 43.3 & 10.8 & 8.7 & 21.6 & 22.0 \\
\hline 5 & 110.0 & 91.9 & 24.9 & 18.9 & 22.5 & 20.5 \\
\hline 6 & 144.0 & 150.0 & 36.4 & 36.3 & 25.3 & 24.0 \\
\hline 7 & 312.5 & 202.0 & 75.4 & 47.0 & 24.0 & 23.1 \\
\hline 8 & 422.5 & 313.5 & 100.9 & 80.7 & 24.0 & 25.8 \\
\hline
\end{tabular}

Data are from Sender (117). 
pansion of total blood volume. This indicates that the expansion of both total blood and red blood cell volumes occurs at maximum speed during normal development.

\section{Influence of Oxygen Pressure on Timing of Switch From Embryonic to Adult Hemoglobin}

As stated in section $\mathrm{I}$, the mechanisms that control the change from embryonic to adult hemoglobin production in the embryo are not yet identified at the molecular level. The question as to what extent epigenetic factors may be involved in the timing of the process has been analyzed in chick embryos grown under different $\mathrm{Po}_{2}(17,117)$. The results of these investigations conclusively demonstrated that ambient $\mathrm{PO}_{2}$ can modulate the timing of the switch.

When embryos are grown under hypoxic conditions definitive red blood cells and consequently adult hemoglobins appear $\sim 24 \mathrm{~h}$ earlier in the circulation than they do in normoxic controls. Conversely, when embryos are incubated under hyperoxic conditions definitive red blood cells are first observed by day 7 of incubation (17, 117), as shown in Figure 10.

Furthermore, it has been shown that these changes are entirely due to alterations of primary yolk sac erythropoiesis (117). The results are most compatible with the idea that the yolk sac harbors two subpopulations of erythroid precursors: one turning invariably into primitive cells, whereas the other can produce definitive as well as primitive red blood cells, depending on the ambient $\mathrm{PO}_{2}$. The total size of the red blood cell population produced from yolk sac precursors is, however, invariant.

In hypoxia one observes an increased production of definitive red blood cells, whereas in hyperoxia all cells turn into primitive red blood cells and the onset of definitive erythropoiesis is linked to the activation of intraembryonic erythropoiesis, which is fed from the permanent stem cell pool (117). In any event the premature appearance of definitive red blood cells in hypoxic embryos has some bearing on the oxygen transport function of the blood, as shown in the next section.

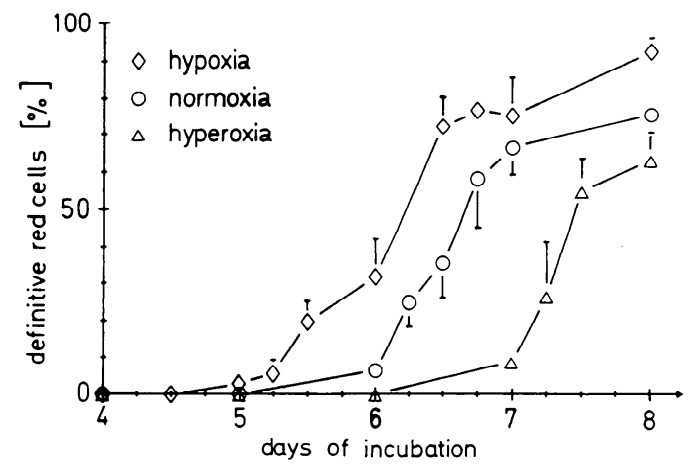

FIG. 10. Influence of ambient $\mathrm{PO}_{2}$ on amount of circulating definitive red blood cells of 4 - to 8-day-old chick embryos (hypoxia, $13.5 \%$ $\mathrm{O}_{2}$; hyperoxia, $100 \% \mathrm{O}_{2}$ )

\section{Influence of Hypoxia on Red Blood Cell-Phosphate Pattern, Carbonic Anhydrase Activity, and Oxygen Affinity}

Unlike the mammalian embryo or fetus where changes in placental blood flow at the maternal side may partially compensate for environmental hypoxia, the avian embryo has no such mechanism at its disposal. This has raised the question as to whether the chick embryo exposed to hypoxia can alter its blood oxygen affinity as an adaptive measure.

Oxygen equilibrium curves determined between days 4 and 9 of development (17) demonstrated that already at day 6 of development the oxygen affinity of the chronically hypoxic embryos was significantly increased compared with normoxic controls. This difference was accentuated during the next few days so that hypoxic chick embryos analyzed at day 9 of development had the same high oxygen affinity as normal embryos after day 14 (8).

It was also recognized that although definitive red blood cells appear earlier in the circulation of hypoxic embryos, there was no convincing correlation between the percent of circulating definitive cells and the oxygen affinity of hypoxic embryos (17). However, analysis of the phosphate pattern demonstrated that under hypoxic conditions there is a rapid reduction of ATP from day 6 of development onward and a concomitant increase of red blood cell 2,3-DPG $(12,15,17)$, which explains at least part of the increase of blood oxygen affinity.

Furthermore, it was observed that the regulation of red blood cell carbonic anhydrase synthesis is coordinated with the change in red blood cell phosphate pattern (15). Thus experimental hypoxia apparently activates a program in definitive red blood cells, which is usually only realized after day 14 of development when progressive hypoxia and hypercapnia develop due to diffusion limitations (125). That blood $\mathrm{PO}_{2}$ has a controlling influence on red blood cell metabolism was also shown by Ingermann et al. (75), who found that they could suppress the switch from ATP to 2,3-DPG and the concomitant increase of the oxygen affinity when late chick embryos were incubated in hyperoxia. Moreover, the repression was entirely reversible. Recent experiments have demonstrated that hyperoxia can also suppress the increase of red blood cell carbonic anhydrase synthesis normally observed after day 14 (98).

The $\mathrm{PO}_{2}$-dependent changes of red blood cell metabolism observed after day 6 of development are not due to a direct effect of oxygen on the red blood cell metabolism but are mediated via circulating plasma factors (98) that under in vitro conditions are able to induce de novo synthesis of carbonic anhydrase and stimulation of 2,3-DPG synthesis at the expense of ATP. The plasma factor is present from day 7 of incubation. Moreover, there seems to be a $\mathrm{PO}_{2}$-dependent control system that can suppress the action of the factor under normoxic conditions that involves phospholipase $\mathrm{C}$ and protein $\mathrm{ki}$ nase $C(98)$. These data are the first evidence that the avian embryo is able to actively respond to hypoxia us- 
ing an $\mathrm{PO}_{2}$-dependent system for the regulation of red blood cell metabolism that is usually (i.e., during normal development) activated after day 14 when $\mathrm{PO}_{2}$ of the chorioallantoic vein progressively decreases. Future work will have to clarify the molecular base of this mechanism and will have to establish if this is a control system universally present in avian embryos. The presence of such a system may have contributed to the fact that birds are able to breed at higher altitudes than all other terrestrial vertebrates.

\section{CONCLUDING REMARKS}

The preceding presentation of the various factors that determine the oxygen transport properties of the embryonic blood and the state of tissue oxygenation is by necessity imperfect. Thus, although the last decade has seen considerable progress in the analysis of embryonic hemoglobin structure, we are still unable to explain the unique oxygen-binding curves found in early embryos in particular with regard to the control of hemoglobin cooperativity. We need to know the intermolecular contact sites involved in the formation of tetramertetramer aggregates of $\mathrm{HbP} / \mathrm{P}^{\prime}$ as well as $\mathrm{HbD}$, and we need to find the elusive metabolites of primitive and early definitive red blood cells that as additional allosteric effectors induce changes in cooperativity and oxygen affinity.

The demonstration of a $\mathrm{Po}_{2}$-regulated system of plasma factors that apparently controls red blood cell metabolism and function after day 6 of development raises a host of questions with regard to cellular mechanism, hormonal transducers, and not least the structures that are responsible for monitoring the $\mathrm{PO}_{2}$.

Finally, more data are needed to analyze the processes involved in the formation and optimization of structure and function of the capillary network of the area vasculosa, the first gas exchange area of the avian embryo.

Against these unresolved questions there is a new body of experimental data that at least at the phenomenological level demonstrates the necessity for the persistance of embryonic hemoglobins, as they possess indeed functional properties uniquely fitted to the needs of the embryo. Furthermore, the results presented once again stress the critical role played by oxygen for the development of the early embryo during the period of organogenesis. There is no doubt that during this period the gas transport system works at the limit of its capacity; thus even small malformations of the circulatory system inside or outside the embryo could have the same consequences for the oxygen availability to tissue as a reduced environmental $\mathrm{PO}_{2}$. Thus the rate of development of the gas transport and circulatory system determines embryonic survival and may at this stage serve as one principal factor of early embryonic selection. This conclusion can be extended to mammalian embryos as well. Meegdes et al. (88) determined the degree of the chorionic vascularization of early human embryos. They found that in spontaneous abortion the incidence of vascularized villi and the vascular density of villi was significantly lower than in legal abortions.

We thank the Deutsche Forschungsgemeinschaft for essential financial support over many years.

\section{REFERENCES}

1. AMMANN, D., F. CANTER, R. A. STEIN, P. SCHULTHESS, Y. SHIJO, AND W. SIMON. Neutral carrier based hydrogen-ion selective microelectrode for extra- and intracellular studies. Anal. Chem. 53: 2267-2269, 1981.

2. AR, A., H. GIRARD, AND P. DEJOURS. Oxygen consumption of the chick embryo's respiratory organ, the chorioallantoic membrane. Respir. Physiol. 68: 377-388, 1987.

3. BARTELS, H., R. BARTELS, T. BRILMAYER, AND W. W. PETERS. Frühentwicklung von Hühnerembryonen bei Normoxie und Hypoxie. Pneumologie 149: 67-73, 1973.

4. BARTLETT, G. R. Phosphate compounds in vertebrate red blood cells. Am. Zool. 20: 103-114, 1980.

5. BARTLETT, G. R., AND T. A. BORGESE. Phosphate compounds in red cells of chicken and duck and hatching. Comp. Biochem. Physiol. A Comp. Physiol. 55: 207-210, 1976.

6. BASSAS, L., M. A. LESNIAK, M. GIRBAU, AND F. DE PABLO. Insulin-related receptors in the early chick embryo: from tissue patterns to possible function. J. Exp. Zool. Suppl. 1: 299-307, 1987.

7. BAUMANN, F. H., AND R. BAUMANN. A comparative study of the respiratory properties of bird blood. Respir. Physiol. 31: 333343, 1977.

8. BAUMANN, R. Regulation of oxygen affinity of embryonic blood during hypoxic incubation. In: Respiration and Metabolism of Embryonic Vertebrates, edited by R. S. Seymour. Dordrecht, The Netherlands: Junk, 1984, p. 221-230.

9. BAUMANN, R. Blood oxygen transport in the early chick embryo. Ergeb. Exp. Med. 53: 127-136, 1990.

10. BAUMANN, R., H. BARTELS, AND C. BAUER. Blood oxygen transport. In: Handbook of Physiology. The Respiralory System. Gas Exchange. Bethesda, MD: Am. Physiol. Soc., 1987, sect. 3, vol. IV, chapt. 9, p. 147-172.

11. BAUMANN, R., AND J. FISCHER. Oxygen binding properties of early definitive red cells from normoxic and hypoxic chick embryos. Adv. Exp. Med. Biol. 191: 485-494, 1985.

12. BAUMANN, R., J. FISCHER, AND M. ENGELKE. Functional properties of primitive and definitive red cells from chick embryo; oxygen binding characteristics, $\mathrm{pH}$ and membrane potential and response to hypoxia. J. Exp. Zool. Suppl. 1: 227-238, 1987.

13. BAUMANN, R., E. GOLDBACH, E. A. HALLER, AND P. G. WRIGHT. Organic phosphates increase the solubility of avian $\mathrm{HbD}$ and embryonic hemoglobin. Biochem. J. 217: 760-771, 1984.

14. BAUMANN, R., AND G. GROS. A comparative study of the aggregation of avian embryonic and adult hemoglobin. In: Hemoglobin, edited by A. G. Schnek and C. Paul. Brussels: Université de Bruxelles, 1984, p. 151-160.

15. BAUMANN, R., E. A. HALLER, U. SCHÖNING, AND M. WEBER. Hypoxic incubation leads to concerted changes of carbonic anhydrase activity and 2,3-DPG concentration of chick embryo red cells. Dev. Biol. 116: 548-551, 1986.

16. BAUMANN, R., S. PADEKEN, AND E. A. HALLER. Functional properties of embryonic chicken hemoglobins. J. Appl. Physiol. 53: 1439-1448, 1982.

17. BAUMANN, R., S. PADEKEN, E. A. HALLER, AND T. BRILMAYER. Effects of hypoxia on oxygen affinity, hemoglobin pattern, and blood volume of early chicken embryos. Am. J. Physiol. 244 (Regulatory Integrative Comp. Physiol. 13): R733-R741, 1983.

18. BEATTIE, J., AND A. H. SMITH. Metabolic adaptation of the chick embryo to chronic hypoxia. Am. J. Physiol. 228: 1346-1350, 1975.

19. BEAUPAIN, D. Line restricted hemoglobin synthesis in chick embryonic erythrocytes. Cell Differ. 16: 101-107, 1985.

20. BEAUPAIN, D., C. MARTIN, AND F. DIETERLEN-LIEVRE. 
Are developmental hemoglobin changes related to the origin of stem cells and site of erythropoiesis? Blood 53: 212-225, 1979.

21. BENESCH, R., AND R. E. BENESCH. The effect of organic phosphates from human erythrocytes on the allosteric properties of hemoglobin. Biochem. Biophys. Res. Commun. 26: 162-167, 1967.

22. BENESCH, R., AND R. E. BENESCH. Intracellular organic phosphates as regulators of oxygen release by hemoglobin. Nature Lond. 221: 618-622, 1969.

23. BENESCH, R., AND R. E. BENESCH. The mechanism of interaction of red cell organic phosphates with hemoglobin. Adv. Protein Chem. 28: 211-237, 1974.

24. BIEBER, F. A., AND G. BRAUNITZER. Die embryonalen Hämoglobine vom Hausschwein (Sus scrofa domestica). HoppeSeyler's Z. Physiol. Chem. 365: 321-334, 1984.

25. BISSONNETTE, J. M., AND J. METCALFE. Gas exchange of the fertile hen's egg: components of resistance. Respir. Physiol. 34: 209-218, 1978.

26. BOMSZTYK, K., AND M. B. CALALB. A new microelectrode for simultancous measurement of $\mathrm{pH}$ and $\mathrm{PCO}_{2}$. Am. J. Physiol. 251 (Renal Fluid Electrolyte Physiol. 20): F933-F937, 1986.

27. BORGESE, T. A., AND R. L. NAGEL. Differential effects of 2,3 DPG, ATP and inositolpentaphosphate on the oxygen equilibria of duck embryonic, fetal and adult hemoglobins. Comp. Biochem. Physiol. A Comp. Physiol. 56: 539-543, 1977.

28. BOUTILIER, R. G., M. A. GIBSON, D. P. TOEWS, AND W. ANDERSON. Gas exchange and acid-base regulation in the blood and extraembryonic fluids of the developing chicken embryo. Respir. Physiol. 31: 81-89, 1977.

29. BRITTAIN, T., AND R. M. G. WELLS. Oxygen transport in early mammalian development: molecular physiology of embryonic hemoglobins. In: Development in Mammals, edited by M. H. Johnson. Amsterdam: Elsevier, 1983, vol. 5, p. 135-154.

30. BROWN, J. L., AND V. M. INGRAM. Structural studies on chick embryonic hemoglobins. J. Biol. Chem. 249: 3960-3972, 1974.

31. BRUNS, G. H. O., AND V. M. INGRAM. The erythroid cell and hemoglobins of the chick embryo. Philos. Trans. R. Soc. Lond. 266: $255-305,1973$

32. BUNN, F. H., AND B. G. FORGET. Hemoglobin: Molecular, Genetic and Clinical Aspects. Philadelphia, PA: Saunders, 1986.

33. CAREY, C. (Editor). Physiology of the avian egg. Am. Zool. 20: 1980.

34. CHAN, L. L. Changes in the composition of plasma membrane proteins during differentiation of embryonic chick erythroid cells. Proc. Natl. Acad. Sci. USA 74: 1062-1066, 1977.

35. CIIAN, L. N. L. Changes in red cell membrane during differentiation. In: Hemoglobins in Development and Differentiation, edited by G. Stamatoyannopoulos and A. W. Nienhuis. New York: Liss, 1981, p. 407-422.

36. CHAPMAN, B. S., L. E. HOOD, AND A. J. TOBIN. Amino acid sequences of the $\epsilon^{-}$and $\alpha^{\mathrm{E}}$-globins of $\mathrm{HbE}$, a minor early embryonic hemoglobin of the chicken. J. Biol. Chem. 257: 643-650, 1982.

37. CHAPMAN, B. S., L. E. HOOD, AND A. J. TOBIN. Minor early embryonic chick hemoglobin M. Amino acid sequences of the $\epsilon$ and $\alpha^{\mathrm{D}}$-chains. J. Biol. Chem. 257: 651-658, 1982.

38. CHAPMAN, B. S., A. J. TOBIN, AND L. E. HOOD. Complete amino acid sequences of the major early embryonic $\alpha$-like globin of the chicken. J. Biol. Chem. 255: 9051-9059, 1980.

39. CHAPMAN, B. S., A. J. TOBIN, AND L. E. HOOD. Complete amino acid sequence of the major early embryonic $\beta$-like globin in chickens. J. Biol. Chem. 256: 5524-5531, 1981.

40. CIROTTO, C., AND I. ARANGI. How do avian embryos breathe? Oxygen transport in the blood of early chick embryos. Comp. Biochem. Physiol. A Comp. Physiol. 94: 607-613, 1989.

41. CIROTTO, C., I. ARANGI, AND F. PANARA. Hemoglobins of developing duck embryos. J. Embryol. Exp. Morphol. 60: 389-404, 1980.

42. CIROTTO, C., AND G. GERACI. Embryonic chicken hemoglobins. Studies on the oxygen equilibrium of two pure components. Comp. Biochem. Physiol. A Comp. Physiol. 51: 159-163, 1975.

43. CIROTTO, C., AND G. GERACI. The hemoglobins of the developing chicken embryo. A system for the study of the switch from fetal to adult hemoglobins. Bull. Mol. Biol. Med. 2: 59-71, 1977.

44. CIROTTO, C., F. PANARA, AND G. GERACI. Two different popu- lations of primitive erythroid cells in the chick embryo. Dev. Biol. 61: 384-387, 1977.

45. CIROTTO, C., A. SCOTTO DI TELLA, AND G. GERACI. The hemoglobin of the developing chicken embryos. Fractionation and globin composition of the individual component of total erythrocytes and a single erythrocyte type. Cell Differ. 4: 87-99, 1975.

46. CLARK, E. B., AND N. HU. Developmental hemodynamic changes in the chick embryo from stage 18 to 27. Circ. Res. 51: 810-815, 1982.

47. CLEGG, J. B., AND J. GAGNON. Structure of the $\zeta$-chain of human embryonic hemoglobin. Proc. Natl. Acad. Sci. USA 78: 60766080,1981

48. CORMIER, F., AND F. DIETERLEN-LIEVRE. The wall of the chick embryo aorta harbours M-CFC, G-CFC, GM-CFC and BFUE. Development 102: 279-285, 1988.

49. CZELUSNIAK, J., M. GOODMAN, D. HEWETT-EMMETT, M. L. WEISS, P. J. VENTA, AND R. E. TASHIAN. Phylogenetic origins and adaptive evolution of avian and mammalian haemoglobin genes. Nature Lond. 298: 297-300, 1982.

50. DAWES, B. M., AND K. SIMKISS. The acid-base status of the blood of the developing chick embryo. J. Exp. Biol. 50: 79-86, 1969.

51. DIETERLEN-LIEVRE, F. On the origin of haemopoietic stem cells in the avian embryo: an experimental approach. J. Embryol. Exp. Morphol. 33: 607-619, 1975.

52. DIETERLEN-LIEVRE, F. Emergence of intraembryonic blood stem cells studied in avian chimeras by means of monoclonal antibodies. Dev. Comp. Immunol. Suppl. 3: 75-80, 1984.

53. DIETERLEN-LIEVRE, F. Respective roles of programs and differentiation factors during hemoglobin switching in the embryo. In: Molecular and Cellular Aspects of Erythropoietin and Erythropoiesis, edited by I. N. Rich. Heidelberg: Springer-Verlag, 1987, p. 127-145.

54. DIETERLEN-LIEVRE, F. Birds. In: Vertebrate Blood Cells, edited by A. F. Rowley and N. A. Ratcliffe. Cambridge, UK: Cambridge University Press, 1988, p. 257-336.

55. DODGSON, J. B., K. C. MCCUNE, D. J. RUSLING, A. KRUST, AND J. D. ENGEL. Adult chicken $\alpha$-globins $\alpha^{\mathrm{A}}$ and $\alpha^{\mathrm{D}}$ : no anemic shock $\alpha$-globin exists in domestic chickens. Proc. Natl. Acad. Sci. USA 78: 5998-6002, 1981.

56. DOLAN, M., B. J. SUGARMAN, J. B. DODGSON, AND J. D. ENGEL. Chromosomal arrangement of the chicken $\beta$-type globin genes. Cell 24: 669-677, 1981.

57. DUHM, J. Effects of 2,3 DPG and other organic phosphate compounds on oxygen affinity and intracellular $\mathrm{pH}$ of human erythrocytes. Pfluegers Arch. 326: 341-356, 1971.

58. ENGEL, J. D., D. J. RUSLING, K. C. MCCUNE, AND J. B. DODGSON. Unusual structure of the chicken embryonic $\alpha$-globin gene,

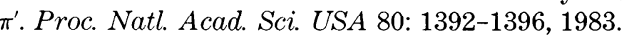

59. ENGELKE, M., W. ZINGEL, AND R. BAUMANN. Membrane potential of primitive red cells from chick embryo is a proton potential. J. Cell. Physiol. 135: 87-93, 1988.

60. FAROQUI, A. M., AND E. R. HUEHNS. Oxygen dissociation studies of red cells from very small human and chicken embryos. In: Internationales Symposium über Struktur und Funktion der Erythrozyten, edited by S. Rapoport and F. Jung. Berlin: Akademie Verlag, 1972, vol. VI, p. 217-220.

61. FREEMAN, B. M., AND M. A. VINCE. Development of the Avian Embryo. London: Chapman \& Hall, 1974, p. 121.

62. GILLESPIE, S. G., AND S. MCHANWELL. Measurement of intraembryonic $\mathrm{pH}$ during the early stages of development in the chick embryo. Cell Tissue Res. 247: 445-451, 1987.

63. GILMAN, J. G. Rat embryonic and fetal erythrocytes. High 2,3biphosphoglycerate and low oxygen affinity in vitro for nucleated embryonic cells. Biochem. J. 192: 335-339, 1980.

64. GIRARD, H. Arterial pressure in the chick embryo. Am. J. Physiol. 224: 454-460, 1973

65. GRIMA, M., H. GIRARD, AND P. DEJOURS. Blood oxygen consumption and erythrocyte types in embryonic and postnatal chicken. Am. J. Physiol. 244 (Cell Physiol. 13): C32-C36, 1983.

66. GRINSTEIN, S., D. ROTIN, AND M. J. MASON. $\mathrm{Na}^{+} / \mathrm{H}^{+}$exchange and growth factor induced cytosolic $\mathrm{pH}$ changes. Role in cellular proliferation. Biochim. Biophys. Acta 988: 73-97, 1989.

67. GROTE, J. Die Sauerstoffdiffusionskonstanten im Lungenge- 
webe und -wasser und ihre Temperaturabhängigkeit. Pfluegers Arch. 295: 245-254, 1967.

68. HAGOPIAN, H. K., AND V. M. INGRAM. Developmental changes of erythropoiesis in cultured chick blastoderms. J. Cell Biol. 51: 440-451, 1971.

69. HAGOPIAN, H. K., J. A. LIPPKE, AND V. M. INGRAM. Erythropoietic cell cultures from chick embryos. J. Cell Biol. 54: 98-106, 1972.

70. HALL, F. G. Haemoglobin function in the developing chick. $J$. Physiol. Lond. 83: 33-37, 1934.

71. HLADKY, S. B., AND T. J. RINK. pH equilibrium across the red cell membrane. In: Membrane Transport in Red Cells, edited by C. Ellory and V. Lew. New York: Academic, 1977, p. 115-136.

72. HOIBY, M., A. AULIE, AND O. B. REITE. Oxygen uptake in fowl eggs incubated in air and pure oxygen. Comp. Biochem. Physiol. A Comp. Physiol. 74: 315-318, 1983.

73. HOLLAND, R. A. B., A. F. RIMES, A. COMIS, AND C. H. TYNDALE-BISCOE. Oxygen carriage and carbonic anhydrase activity in the blood of a marsupial, the Tammar wallaby (Macropus eugenii) during early development. Respir. Physiol. 73: 69-86, 1989.

74. HU, N., AND E. B. CLARK. Hemodynamics of the stage 12 to stage 29 chick embryo. Circ. Res. 65: 1665-1670, 1989

75. INGERMANN, R. L., M. K. STOCK, J. METCALFE, AND T. B. SHIH. Effect of ambient oxygen on organic phosphate concentrations in erythrocytes of the chick embryo. Respir. Physiol. 51: 141-152, 1983.

76. ISA ACKS, R. E., AND D. R. HARKNESS. 2,3-Diphosphoglycerate in erythrocyte of chick embryos. Science Wash. DC 189: 393394, 1975 .

77. ISAACKS, R. E., AND D. R. HARKNESS. Erythrocyte organic phosphates and hemoglobin function in birds, reptiles, and fishes. Am. Zool. 20: 115-129, 1980.

78. JELKMANN, W., AND C. BAUER. Embryonic hemoglobins: dependency of functional characteristics on tetramer composition. Pfluegers Arch. 377: 75-80, 1978.

79. KAYAR, S. R., G. K. SNYDER, G. F. BIRCHARD, AND C. P. BLACK. Oxygen permeability of the shell and membranes of chicken eggs during development. Respir. Physiol. 46: 209-221, 1981.

80. KREGENOW, F. M. Transport in avian red cells. In: Membrane Transport in Red Cells, edited by J. L. Ellory and V. L. Lew. New York: Academic, 1977, p. 383-426.

81. KUTCHAI, H., AND J. B. STEEN. Permeability of the shell and shell membranes of the hen's eggs during development. Respir. Physiol. 11: 265-278, 1971.

82. LAPENNAS, G. N., AND B. R. REEVES. Oxygen affinity and equilibrium curve shape in blood of chicken embryos. Respir. Physiol. 52: 13-16, 1983.

83. LASSEN, U. V. Electrical potential and conductance of the red cell membrane. In: Membrane Transport in Red Cells, edited by J. L. Ellory and V. L. Lew. New York: Academic, 1977, p. 237-272.

84. LASSILA, O., C. MARTIN, P. TIOVANEN, AND F. DIETERLENLIEVRE. Erythropoiesis and lymphopoiesis in the chick yolksac-embryo chimeras: contribution of yolk sac and intraembryonic stem cells. Blood 59: 377-381, 1982.

85. LOIS, R., AND H. G. MARTINSON. Chicken globin gene transcription is cell lineage specific during the time of the switch. Biochemistry 28: 2281-2287, 1989.

86. LOMHOLT, J. P. A preliminary study of local oxygen tensions inside bird eggs and gas exchange during early stages of embryonic development. In: Respiration and Metabolism of Embryonic Vertebrates, edited by R. S. Seymour. Dordrecht, The Netherlands: Junk, 1984, p. 289-297.

87. MARTIN, C., D. BEAUPAIN, AND F. DIETERLEN-LIEVRE. Developmental relationships between vitelline and intra-embryonic haemopoiesis studied in avian yolk-sac chimeras. Cell Differ. 7: 115-130, 1978.

88. MEEGDES, B. H. L. M., R. INGENHOES, L. L. PEETERS, AND N. EXALTO. Early pregnancy wastage: relationship between chorionic vascularization and embryonic development. Fertil. Steril. 49: $216-220,1988$.

89. METCALFE, J., I. E. MCCUTCHEON, D. L. FRANCISCO, A. B.
METZENBURG, AND J. E. WELCH. Oxygen availability and growth of the chick embryo. Respir. Physiol. 46: 81-88, 1981.

90. METCALFE, J., M. K. STOCK, AND R. L. INGERMANN (Editors). Development of the Avian Embryo. New York: Liss, 1987.

91. MEUER, H. J., AND R. BAUMANN. Oxygen supply of early chick embryo in normoxia and hypoxia. J. Exp. Zool. Suppl. 1: 203-207, 1987.

92. MEUER, H. J., AND R. BAUMANN. Oxygen pressure in intraand extraembryonic blood vessels of early chick embryo. Respir. Physiol. 71: 331-342, 1988

93. MEUER, H. J., AND C. BERTRAM. RBC transit time in capillary mesh networks of early embryonic respiratory organ (Abstract). Int. J. Microcirc. Clin. Exp. 8, Suppl. 1: S53, 1989.

94. MEUER, H. J., AND C. EGBERS. Changes in density and viscosity of chicken egg albumen and yolk during incubation. J. Exp. Zool. 255: 16-21, 1990.

95. MEUER, H. J., V. HARTMANN, AND S. JOPP. Tissue $\mathrm{PO}_{2}$ and growth rate in early chick embryos. Respir. Physiol. In press.

96. MEUER, H. J., U. SIEGER, AND R. BAUMANN. Measurement of $\mathrm{pH}$ in blood vessels and interstitium of 4 and 6 day old chick embryos. J. Dev. Physiol. 11: 354-359, 1989.

97. MEUER, H. J., AND P. TIETKE. Changes in blood $\mathrm{PCO}_{2}$ and acidbase status in chick embryo between day 4 and 6 of incubation. Adv. Exp. Med. Biol. 277: 751-758, 1990.

98. MILLION, D., P. ZILLNER, AND R. BAUMANN. Oxygen pressure dependent control of carbonic anhydrase synthesis in chick embryonic red cells. Am. J. Physiol. 261 (Regulatory Integrative Comp. Physiol. 30): R1188-R1196, 1991.

99. MOORMAN, A. F. M., M. P. A. SCHALEKAMP, P. A. J. DEBOER, W. J. C. GEERTS, W. H. LAMERS, AND R. CHARLES. Immunohistochemical analysis of the distribution of histone $\mathrm{H} 5$ and hemoglobin during chicken development. Differentiation 34 : 161-167, 1987.

100. MORROW, J. S., R. S. WITTEBORT, AND F. R. N. GURD. Liganddependent aggregation of chicken hemoglobin $\mathrm{A}_{\mathrm{I}}$. Biochem. Biophys. Res. Commun. 60: 1058-1065, 1974.

101. NIELSEN, N. W. Microangiography in explanted chick embryos. Microvasc. Res. 22: 156-170, 1981.

102. ORKIN, S. H. Cell-specific transcription and cell differentation in the erythroid lineage. Curr. Top. Cell Biol. 2: 1003-1012, 1990.

103. PAGANELLI, C. V. The physics of gas exchange across the avian eggshell. Am. Zool. 20: 329-338, 1980.

104. PIIPER, J. (Editor). Respiratory Function in Birds, Adult and Embryonic. Berlin: Springer-Verlag, 1978.

105. POPP, R. A., C. L. MARSH, AND L. C. SKOW. Expression of embryonic hemoglobin genes in mice heterozygous for $\alpha$-thalassemia or $\beta$-duplication traits and in mice heterozygous for both traits. Dev. Biol. 85: 123-128, 1981.

106. RADDATZ, E., AND P. KUCERA. Mapping of the oxygen consumption in the gastrulating chick embryo. Respir. Physiol. 51: 153-166, 1983.

107. RAHN, H., A. AR, AND C. V. PAGANELLI. How bird eggs breathe. Sci. Am. 240: 38-47, 1979.

108. RAMSEYER, L. T. H., J. BARKER-HARREL, D. J. SMITH, K. A MCBRIDE, R. N. JARMAN, AND R. H. BROYLES. Intracellular signals for developmental hemoglobin switching. Dev. Biol. 133: 262-271, 1989.

109. REEVES, R. B. Blood oxygen affinity in relation to yolk-sac and chorioallantois gas exchange in the developing chick embryo. In: Respiration and Metabolism of Embryonic Vertebrates, edited by R. S. Seymour. Dordrecht, The Netherlands: Junk, 1984, p. 231244.

110. RIGGS, A. The Bohr effect. Annu. Rev. Physiol. 50: 181-204, 1988.

111. ROMANOFF, A. L. Biochemistry of the Avian Embryo. New York: Wiley, 1967, p. 137-141.

112. ROMANOFF, A. L. Pathogenesis of the Avian Embryo. New York: Wilcy, 1972, p. 96-99.

113. ROMIJN, C., AND W. LOCKHORST. Foetal respiration in the hen. Int. J. Comp. Physiol. Ecol. 2: 187-197, 1951.

114. RONINSON, I. B., AND V. M. INGRAM. Gene evolution in the chicken $\beta$-globin cluster. Cell 28: 515-521, 1982.

115. RONINSON, I. B., AND V. M. INGRAM. Expression and partial 
sequence of the chicken $\beta^{\mathrm{H}}$-globin gene. J. Biol. Chem. 258: 802$809,1983$.

116. SCHNEK, A. G., C. PAUL, AND J. LEONIS. Evolution and adaptation of avian and crocodilian hemoglobins. In: Respiratory Pigments in Animals, edited by J. Lamy, J. P. Truchot, and R. Gilles. Berlin: Springer-Verlag, 1984, p. 141-158.

117. SENDER, S. Immunfluoreszenzuntersuchungen zur primitiven und definitiven Erythropoese bei $4-8$ Tage alten normoxischen, hypoxischen und hyperoxischen Hühnerembryomen ( $\mathrm{PhD}$ thesis). Hannover, FRG: University of Hannover, 1990.

118. SEYMOUR, R. S. (Editor). Respiration and Metabolism of Embryomic Vertebrates. Dordrecht, The Netherlands: Junk, 1984.

119. SEYMOUR, R. S., AND J. PIIPER. Aeration of shell membranes of avian eggs. Respir. Physiol. 71: 101-116, 1988.

120. SHIMIZU, K. Identification of hemoglobin types contained in single chicken erythrocytes by fluorescent antibody technique. Dev. Biol. 48: 317-326, 1976.

121. SIEGER, U. Untersuchungen zum Einfluss von $\mathrm{CO}_{2}$ auf den extrazellulären $p H$ in Gefässen und Interstitium 4 und 6 Tage alter Hühnerembryonen und zur Regulation des Zell-pH immaturer embryonaler Erythrozyten (PhD thesis). Regensburg, FRG: University of Regensburg, 1990.

122. STEWART, D. E., M. L. KIRBY, AND K. K. SULIK. Hemodynamic changes in chick embryos precede heart defects after cardiac neural crest ablation. Circ. Res. 59: 545-550, 1986.

123. STRATIL, A., AND M. VALENTA. Ontogenetic changes in the haemoglobins of geese, ducks, chickens and turkeys. Comp. Biochem. Physiol. B Comp. Biochem. 55: 145-149, 1976.

124. TAZAWA, H. Measurement of respiratory parameters in blood of chicken embryo. J. A ppl. Physiol. 30: 17-20, 1971.

125. TAZAWA, $\mathrm{H}$. Oxygen and $\mathrm{CO}_{2}$ exchange and acid-base regulation in the avian embryo. Am. Zool. 20: 295-404, 1980.

126. TAZAWA, H. Carbon dioxide transport and acid-base balance in chickens before and after hatching. In: Respiration and Metabolism of Embryonic Vertebrates, edited by R. S. Seymour. Dordrecht, The Netherlands: Junk, 1984, p. 333-345.

127. TAZAWA, H., T. MIKAMI, AND C. YOSHIMOTO. Respiratory properties of chicken embryonic blood during development. Respir. Physiol. 13: 160-170, 1971.

128. TIEN, O., C. V. PAGANELLI, H. RAHN, AND R. R. JOHNSON.
Influence of eggshell pore shape on gas diffusion. J. Exp. Zool. Suppl. 1: 181-186, 1987.

129. TULLETT, S. G. The effect of eggshell porosity on blood-gas and acid-base status of domestic fowl embryos within the egy of the same weight. Comp. Biochem. Physiol. 81: 137-142, 1985.

130. VISSCHEDIJK, A. H. J., H. TAZAWA, AND J. PIIPER. Variability of shell conductance and gas exchange of chicken eggs. Respir. Physiol. 59: 339-345, 1985.

131. WANGENSTEEN, O. D., AND H. RAHN. Respiratory gas exchange by the avian embryo. Respir. Physiol. 11: 31-45, 1970/71.

132. WANGENSTEEN, O. D., H. RAHN, R. R. BURTON, AND A. H. SMITH. Respiratory gas exchange of high altitude adapted chick embryos. Respir. Physiol. 21: 61-70, 1974.

133. WANGENSTEEN, O.D., AND E. R. WEIBEL. Morphometric evaluation of chorioallantoic oxygen transport in the chick embryo. Respir. Physiol. 47: 1-20, 1982.

134. WANGENSTEEN, O. D., D. WILSON, AND H. RAHN. Diffusion of gases across the eggshell of the hen's egg. Respir. Physiol. 11: $16-30,1970 / 71$.

135. WEBER, R. E., T. KLEINSCHMIDT, AND G. BRAUNITZER. Embryonic pig hemoglobins Gower I $\left(\zeta_{2} \epsilon_{2}\right)$, Gower II $\left(\alpha_{2} \epsilon_{2}\right)$, Heide I $\left(\zeta_{2} \delta_{2}\right)$ and Heide II $\left(\alpha_{2} \delta_{2}\right)$ : oxygen binding functions related to structure and embryonic oxygen supply. Respir. Physiol. 69: 347$357,1987$.

136. WISPÉ, J., N. HU, AND E. B. CLARK. Effect of environmental hypothermia on dorsal aortic blood flow in the chick embryo, stages 18 to 24. Pediatr. Res. 17: 945-948, 1983.

137. YOSHIDA, H., F. MANASEK, AND R. A. ARCILLA. Intracardial flow patterns in early embryonic life. Circ. Res. 53: 363-371, 1983.

138. ZAGRIS, N. Cellular interactions and/or random differentiation for the formation of erythroid cells in the early chick embryo. In: Molecular and Cellular Aspects of Erythropoietin and Erythropoiesis, edited by I. N. Rich. Heidelberg: Springer-Verlag, 1987, p. $147-163$.

139. ZAHKA, K. G., N. HU, K. P. BRIN, F. C. P. YIN, AND E. B. CLARK. Aortic impedance and hydraulic power in the chick embryo from stages 18 to 29. Circ. Res. 64: 1091-1095, 1989.

140. ZWEIFACH, B. W., AND H. H. LIPOWSKY. Quantitative studies of the microcirculatory structure and function. III. Microvascular hemodynamics of cat mesentery and rabbit omentum. Circ. Res. 41: 380-390, 1977. 